\title{
A bibliography of six foreign plant collectors (Imai, Mills, Furumi, Nomura, Saito, and Okuyama) in North Korea
}

\author{
Chin-Sung Chang ${ }^{1 *}$, Hye-Won Kim ${ }^{1}$ and Hui Kim² \\ ${ }^{1}$ Department of Forest Sciences and The Arboretum, College of Agriculture and Life Sciences, Seoul National University, Seoul, 151-742 \\ ${ }^{2}$ Department of Medicinal Plants Resources, Mokpo National University, Muan-gun, Jeollanam-do, 534-729, Korea
}

(Received 5 January 2016; Revised 6 March 2016; Accepted 14 March 2016)

\author{
한반도 북부 채집을 시도한 외국인 6 명과 지명 정리: \\ Imai, Mills, Furumi, Nomura, Saito, Okuyama \\ 장진성'* · 김혜원 ${ }^{1} \cdot$ 김휘 ${ }^{2}$ \\ ${ }^{1}$ 서울대학교 농업생명과학대학 산림과학부 및 수목원, ${ }^{2}$ 목포대학교 응용생명공학부 생약자원전공
}

\begin{abstract}
Korean Peninsula Flora Database (KPF database), developed by T.B. Lee Herbarium of Seoul National University comprises ca. 65,000 accessions of vascular plants collected from Korean peninsula from 1850 to 1945. Among these, material from North Korea (Democratic People's Republic of Korea) is represented with ca. 33,000 accessions. The largest part of this material [ca. 4287 accessions (13\%) from North Korea] originates from five Japanese and one American collectors, such as Imai, Hanjiro, Mills, Ralph Garfield, Furumi, Masatomi, Nomura, Naohiko, Saito, Tatsumoto, and Okuyama, Shunki from 1909 to 1942 . These data are the third largest holding (13\%) of North Korean collections after Komarov, V.L and Nakai, T. A part of scientific report about the results of these expeditions had been published before, but the present publication set it sights on giving a first overview of the itineraries and the materials collected by five collectors in North Korea. Among these, Saito has by far the largest collection with 1,730 specimens, followed by five collectors in order with 1,067, 532, 510, 368 and 370 accessions by Mills, Nomura, Okuyama, Furumi, and Imai respectively.
\end{abstract}

Keywords: Gazetteer, North Korea (Democratic People's Republic of Korea), H. Imai, R. Mills, M. Furumi, N. Nomura, T. Saito, S. Okuyama

적 요 : 서울대학교 수우표본관에서 완성한 KPF(Korean Peninsula Flora Database) 데이터베이스에서는 1850 년부터 1945 년까지 한반도에서 채집된 65,000 개의 관속식물의 기록물을 관리하고 있다. 이 중 북한에서 채 집된 기록은 33,000 개인데 이 중 $13 \%$ 에 해당되는 4,287 개가 1909 년부터 1942 년에 걸쳐 5 명의 일본인(노무라, 오쿠야마, 후루미, 이마이, 사이토)과 1 명의 미국인(밀즈)에 의해 채집되었다. 코마로프(Komarov, V.L), 나카이 (Nakai, T) 이후 3 번째로 많은 북한에서 채집된 표본이다. 이런 채집과 관련된 보고서는 지명사전으로 기존 에 일부 발표하였지만, 본 논문에서는 보다 더 자세한 일정과 채집물에 대해 기록하였다. 사이토가 가장 많 은 1,730 개 표본을 채집하였고 밀즈, 노무라, 오쿠야마, 후루미, 이마이 순서로 $1,067,532,510,368,370$ 개의 표본을 채집하였다.

주요어 : 지명사전, 북한, 이마이, 밀즈, 후루미, 노무라, 사이토, 오쿠야마

*Author for correspondence: quercus@plaza.snu.ac.kr 
생물다양성정보학(Biodiversity informatics)은 채집된 표 본 자료나 종발생 자료, 문헌, 사진 기록 등을 1 차 종발생 자료(primary occurrence data)로 정보화하여 다양성 보전에 활용하고 있다(Pollefeys et al., 2004; Museum of Vertebrate Zoology and Geospatial Innovation Facility, 2008; Haripersaud et al., 2010; Tang et al., 2010; Feeley and Silman; GBIF, 2011).

생물다양성 정보의 활용도는 종발생자료에 위치정보 를 부여하는 과정에서 더 확장된다. 위치정보를 부여하기 위해서는 지명정보를 정리하는 작업이 필요하고, 과거 지 명의 불일치, 불확실함, 혼란 등을 해결하기 위해 여러 언 어로 표기된 지명을 모아 정리하고 좌표를 입력하는 작업 으로 지명과 관련된 통일된 'Gazetteer'(지명사전)라 지칭 한다. 하버드대학에서 중국 운남과 티벳 지역의 과거 지 명에 대한 정리를 DB화해서 제시하고 있으며(Kelly, 2006; Boufford et al., 2013), 유럽이나 남미에서도 일부 산발적으 로 이런 작업을 시도하고 있다.

1945년 이전 한반도 내에서 채집된 식물 표본은 대부분 일본에 소장되어 있어 표본 레이블에 대부분 한자로 기록 되어 있어, 어느 정도 지역에 대한 정보를 유추해서 자료 활용이 가능하다. 그러나 일제 강점기 문헌에는 한자 지 명을 일본식 발음으로 표기하여 문헌과 표본에 대한 정보 의 상호보완이 되지 않아 이용 빈도가 낮다(Chang et al., 2015).

1947년과 1952년 두 차례의 북한 행정개편은 과거 사용 한 많은 지명들이 소멸되어, 과거와 현재의 지명 정보의 괴리가 점차 심화되고 있다(Kim et al., 2006). 외국에서는 이런 이유로 여전히 문헌에 기록된 과거 일본식 발음의 북한 지명을 활용하고 있으며, 정확한 위치참조를 위해서 국내 전문가에게 의뢰하기도 하지만 외국처럼 발달된 지 리참조연산 시스템이 구축되어 있지 않아 정확한 정보를 제공하는데 한계가 있다.

국내 채집지명과 채집자들의 채집행적 정리는 과거 발 표를 통해 V. Komarov (Chang and Chang, 2003; Chang and Choi, 2004), U. Faurie (Chang et al,, 2004), T. Nakai (Kim et al., 2006), T. Uchiyama (Kim et al., 2007), T. Ishidoya (Chang and Chang, 2010), E. H. Wilson (Kim et al., 2010), T. Mori (Kim et al., 2012), J. Ohwi, S. Kitamura와 G. Koidzumi (Chang et al., 2013)등의 채집지명을 정리한 바 있다. 이런 채집행적 정리는 지명정리의 가장 초기 단계의 작업으로 써 기록된 채집 날짜와 지명 등의 흔하게 발견되는 일차 적인 오류를 잡아내고 지명 정리하는데 핵심이 된다.

본 연구는 주로 과거 북한 지역에서 채집을 시도한 지역 별 대표가 되는 6명에 대한 자료로 주로 1910년대 채집자 3 명, 1930년대 2명, 1940년대 1명에 대한 자료이다. 기존 이런 자료는 이미 지명사전으로 일부 채집자별 기록은 정 리되었으나(Chang et al., 2015), 본 연구에서는 보다 자세 하게 해당 채집자의 채집날짜와 표본에 대한 기록을 정리 하였다.
Imai, Hanjiro (今井牛次郎)는 하버드대학 데이터베이스 (Harvard University Herbaria \& Libraries, 2015)에서는 첫 채 집은 1920년, 마지막 채집은 1929년으로 기록하지만 실제 채집은 1909년부터 시도하였다. 평양고등보통학교 교사 로 재직한 것으로 알려져 있다. 일본에서는 지질 분야에 今井斗次郎(1884-1938)로 기록되는 인물과 동일 인물로 추정되며 이 기록이 맞을시, 당시 25-28세 사이로 추정된 다. 평안남도와 평안북도 지역을 주로 채집하였다.

Mills, Ralph Garfield (1884-1944)는 1884년 미국 일리노 리 링컨에서 출생한 의사로서, 1908년-1918년까지 약 10 년 간 한국에서 그의 나이 20-30대에 선교 활동을 하였다 (Yeo, 2004). 세브란스병원의 연구부에서 보건 분야 연구 를 하였지만, 초기에는 현재의 자강도(당시 평안북도) 강 계에서 선교 및 의사 생활을 하면서 약 3년 간(1909년1911년) 채집활동을 하였다. 1918년에 한국을 떠나 6년간 북경에 머물다가, 1924년에 미국으로 귀국했다. 북경에 머물던 시기인 1921년과 1922년 여름에 두 차례 황해도 구 미포와 몽금포에서 채집 활동한 기록이 확인된다. 60 세인 1944년에 미국 일리노이에서 사망하였다.

Furumi, Masatomi (古海正福)은 1888년생으로 制松江高 校(현재 島根県 島根大學)의 식물학 교수를 지냈으며 42 세인 1930년에 사망하였다. 주로 자강도-양강도 지역 채 집을 시도하였다.

Nomura, Naohiko (野村直彦)은 1926-1935년에 함경남 도 함흥고등보통학교 교사로 지냈으며, 이후 1937-1939 년 3년 간 함경남도 농사시험장에서 기수로, 1940-1941년 에는 전라북도 농사시험장 기수로 활동한 기록이 나오지 만 출생과 사망에 대한 정보는 존재하지 않는다. 주로 함 경남도 함흥 주변의 채집을 시도하였다.

Saito, Tatsumoto (斉藤龍本)은 1889년 생으로 큐슈 (Kyushu), 구마모토(Kumamoto) 출신으로 1913년에 조선 에 들어와 중간에 잠시 취업을 하였지만, 1935년까지 함 경북도 나남에서 약국을 운영하였다. 이후 약 10 년 간 임 업과 과학박물관에서 일을 하다 1945년 2차 세계대전 종 전 후에는 구마모토로 돌아가 58년까지 대학과 제약회사 에 근무하였다. 주로 한반도에서 함경남북도와 지금의 양 강도 지역을 주로 채집하였다. 1961년 72세에 사망하였다 (Kitamura, 1977).

Okuyama, Shunki (Syunki) (奥山春李) (1909-1998)는 일 부 도감 집필을 한 기록이 나오지만[原色日本野外植物 図譜, 茶花植物図鑑, Terasaki's Illustrated Flora of Japan] 일 본 자연사박물관에서 활동한 이외에는 자세한 이력은 알 려져 있지 않다. 31세인 1940년 8월에 약 10일간 주로 강원 도 금강산과 함경남도 남쪽 채집을 시도하였다.

본 연구는 1910년에서 1945년까지 한반도 채집을 시도 한 6 명의 채집 행적을 종합적으로 정리하여, 추후 북한에 분포하는 식물 채집 기록의 일차종발생자료의 디지털화 에 활용하고자 시도하였다. 


\section{재료 및 방법}

1984년도에 이우철 교수가 기록한 경도대학 표본관 소재 한반도 채집표본 카드정보(이우철 카드)와 발표 연 구 논문(Nakai, 1912)에 언급된 채집 기록에 소장된 자료 를 직접 조사하여 정리하였다. 영국 Oxford 대학에서 개 발한 브라암스(Botanical Research And Herbarium Management System; BRAHMS, 2015)에 입력해서 분석 하였다. 지명에 대한 정리 부분과 문헌 출처에 대해서는 기존 연구 결과(Chang et al., 2015)을 참고하였다.

입력은 문헌에 언급된 채집지명, 출처 등을 정리하였 다. 표본에 기재되어 있는 한자지명과 이들이 발표한 문 헌에 기재되어 있는 로마자화 된 지명을 입력하여 정리 하였다. 채집지 위치는 GeoNames (http://www.geonames .org/1835841/southkorea.html; http://www.geonames.org/ $1873107 /$ north-korea.html)에서 확인하고, 구글맵(google map; maps. google.co.kr/)을 이용하거나 지리참조연산을 통하여 좌표화하였다(Chang et al., 2015). 북한의 경우는 1945년 이후 많은 행정지명, 특히 도와 군 이름이 급격히 변화하여 1945년 8월 15일을 기준으로 작성된 '한국지명 사전(Sohn, 1974)'을 기준으로 하였고, 남한은 2013년 7 월 현재 지명을 기재하였다. 기재된 지명 확인을 위해 활 용된 지도는 지리부도 (Park et al., 2002)와 국토지리정보 원에서 제공하는 대한민국전도(NGII, 2009)이며 한국학 자료포털의 고지명용례(The Academy of Korean Stuydies, 2009)와 '북한지역정보넷' [http://www.cybernk .net/]을 참고하였다. 분포도는 DIVA-GIS (Hijimans, 2011)을 이용하여 그렸다.

\section{결과 및 고찰}

서울대학교 수우표본관에서 관리하는 한반도 데이터 베이스(Korean Peninsula Flora database (KPF))에 정리된 전 체 숫자 약 65,000 개 중 북한에서 채집된 표본이나 문헌 기 록 숫자는 약 절반인 33,000 개이며(50.4\%), 본 연구에서 분 석된 6 명의 기록은 북한 채집품 중 $13 \%(4,287$ 개)를 차지한 다. 한반도 채집중 개인 채집품 중에는 Komarov (7,169개), Nakai $(6,777$ 개), Ohwi (3,461개) 등의 다량의 채집기록이 있지만 전체 숫자로는 6 명 채집 전체가 3 번째 많은 채집 품 숫자가 된다.

아래 채집자는 주요 채집의 연도 기록을 근간으로 순서 대로 정리하였고 문헌에 나온 지명은 Table 1에 제시하였 다. 문헌에 나온 출처는 기존 연구 발표 책자에 정리하여 이미 발표하였다(Chang et al., 2015).

1. Imai Hanjiro (今井牛次郎): 1909년부터 1912년까지 4 년 동안 평안남북도를 중심으로 채집을 시도하였는데, 주 로 5-8월에 채집 표본이 집중된다. 도쿄대학 표본관(TI)에
는 590개 표본이 소장되어 있으며, 370 개 표본이 평양에서 채집되어 전체의 $63 \%$ 를 차지한다. 주로 1912년 채집인 평 안북도 영변군과 벽동군 및 자강도 초산 채집품은 141 개 로 $24 \%$ 가 된다. 이 중 35 개가 Nakai에 의해서 기준표본으 로 인용하였다. 아래 기록은 Chang et al. (2015)에 기록된 내용을 재정리하였다(Appendix 1).

\section{[1909년]}

평양 시내를 중심으로 대동강변과 모란봉(牡丹臺), 송 라산, 보통강변에서 6 월 22일부터 10 월 10 일까지 채집한 기록이 있다. 100 개 채집품이 남아 있다.

\section{[1910년]}

4월부터 평양의 보통강변, 모단대, 을밀대, 그리고 진남포 비발도를 중심으로 채집을 하였다. 104개 채집품이 있다.

\section{[1911년]}

5 월 -10 월 사이 평양, 용악산에서의 채집기록이 있다. 8 월에는 평안남도 개천과 황해도 해주, 황주에서의 채집기 록이 극히 일부 남아 있다. 127 개 채집품이 있다.

\section{[1912년]}

5 월 평양과 대성산에서 채집된 표본기록이 있다. 6월 말 부터 용강, 강서, 남포, 개천, 철산에서 채집하였고, 7월말 부터 한 달 간, 평안북도 영변, 8월 초에는 평안북도 운산초산-고산령-벽동-창성-삭주를 거쳐 의주까지 채집하였 다. 9월에는 다시 평양에서의 채집 기록이 있다. 258 개 채 집품이 남아 있다.

2. Mills, Ralph Garfield: 1909년부터 1914년까지 5년간 한반도의 채집을 시도하였으며, 이후 1921-1922년 황해 남도 채집 기록이 있다. 한반도에서 채집한 표본 수는 약 15,000 개라 알려져 있지만(Yeo, 2004), 현재 동경대학에 소 장된 표본은 1,067 개만 기록으로 남아 있으며, 일부 北京 Academia Sinica (PE)에 소장되어 있다(Chang et al., 2015).

자강군 강계군에서 355 건, 황해남도 용연군에서의 333 건의 표본이 남아 있다. $70 \%$ 표본이 대부분 강계나, 황해 도 몽금포, 구미포(소래) 등이며 극히 일부가 평안북도의 안주, 희천, 삭주, 창성, 위언, 박천 지역 등의 채집 기록이 있다. 1911년 이후(1912-1914년) 채집품 중 서울과 부산 채집품이 168 개 정도 남아 있다.

채집품은 강계를 비롯해서 당시 Nakai는 그의 9개 정 도의 서울, 안주, 소래에서 채집된 표본을 기준표본으로 사용하였다. Nakai(1912)는 약 250개의 표본을 가지고 Plantae Millsianae Koreanae라는 제목으로 종목록을 제시 하였는데 이는 1911년 인쇄한 Flora Koreana II 에 누락된 표본에 대한 조사가 된다. 데이터베이스 자료 분석을 보 


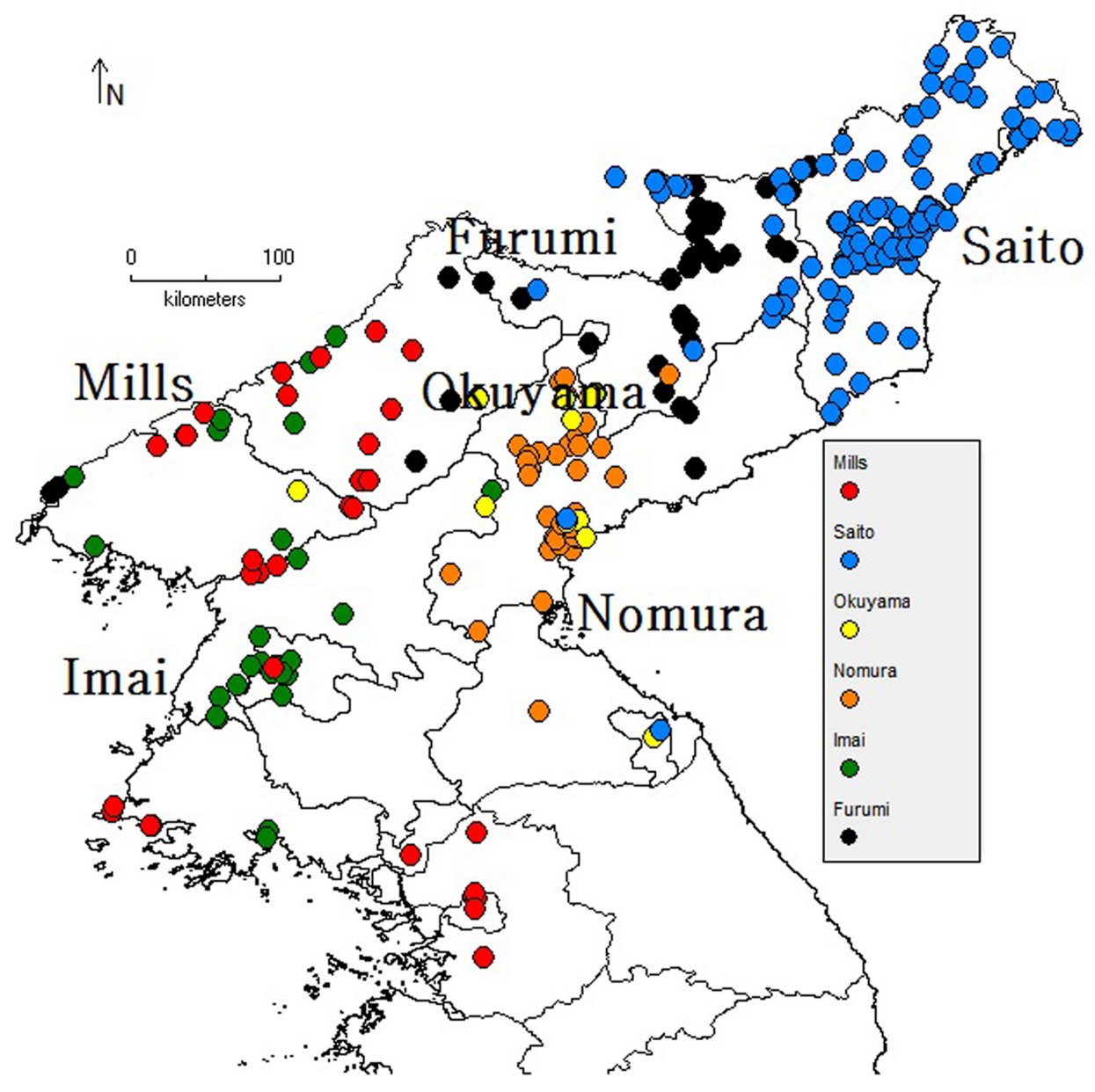

Fig. 1. Six collectors' trip in North Korea. Six different colors on the map and legend refer to the localities surveyed by six collectors in the gazetteer from 1909 to 1942 .

면 Mills은 Faurie/Taquet과 유사하게 채집된 표본별로 정 리 후에 표본번호를 부여하는 방식을 선택해서 채집날 짜에 대한 오류가 상당히 많이 확인된다. 지명 중 매우 간략하게 기록되어 채집지에 대한 추정이 다소 어려운 경우가 있다.

Nakai의 경우는 같은 논문에서도 동일 지명을 달리 표 기하는 경우가 많아 Quang Chee Pah Wee, Kai Aw Gai Pass (筐地, 광지바위)나, Kang-gei, Kangei, Kokai (汇界)로 표 시하는 경우가 있다. 이외에도 일부 지명은 채집동선과 날짜를 고려해서 추정한 장소는 개성지역인 Myo Daug (妙德), 경기도 연천의 Wolgok (月夰) 등이 존재한다. 현 재 논문에서 제시한 그림(Fig. 1)은 북한을 중심으로 채집 된 지역만을 표시하였다(Appendix 2 참조).

[1909년]

5 월-7월까지 평안북도 강계군에서의 표본이 있으며, 8 월 15 일 -18 일은 자강도 전천, 25 일은 평양에서의 채집 기록이 있다. 9월 초에는 서울에서 채집된 표본이 남아 있다.

\section{[1910년]}

4월에 평안남도 안주 지역 채집을 시도하였으며 부터 4-8월까지 평안북도 강계군을 중심으로 채집을 하였다. 8 월 중순에는 자강도 시중동, 초산, 평안북도 벽동에서 채 집을 하였다. 이후 9월 말부터 평양, 평안남도 안주시 신안 과 평안북도 서동, 향산으로, 자강도인 희천과 강계로 이 동하면서 채집을 하였다. 즉 8 월 중순에 강계에서 이동해 서 평양으로 이동한 후, 한 달 후에 강계로 돌아오는 일정 의 채집으로 추정된다.

\section{[1911년]}

3월부터 8월까지 평안남도 강계에서의 표본이 남아 있 다. 8월 말에는 자강도 시중동, 위원, 평안북도 창성, 삭주, 전천으로 이동한 채집 기록이 남아 있다. 9월과 10 월에는 서울과 부산 채집기록이 남아 있다.

[1912년-1914년]

1912년 초에는 부산에서의 채집 기록이, 1913년 11월과 1914년에는 주로 서울(북한산)에서 채집기록이 남아있다. 
7월에는 경기도 연천과 황해남도 구미포 채집기록이 있다.

[1921년]

6월 말에서 8월초까지 황해도 구미포에서 채집한 기록 이 있다.

[1922년]

1921년과 유사하게 6월말에서 7월 말까지 황해도 구미 포 채집이 남아 있고, 그 이후 몽금포와 개성의 묘덕의 채 집 표본이 있다.

3. Furumi, Masatomi (古海正福): 1917년 4월부터 9월까 지 약 5 개월 동안 평안북도, 함경남도와 함경북도를 주로 조사하였으며, 그가 채집한 368 개의 표본이 도쿄대학 표 본관(TI)에 소장되어 있는 것으로 확인되며, 그 중에서 11 개의 표본이 Nakai에 의해서 기준표본으로 지정되었다. 백두산 채집기록이 다수 남아 있어, 이 지역 초기 식생 연 구에 중요한 자료가 된다(Appendix 3 참조).

\section{[1917년]}

4월에는 신의주 근처 채집을 시도한 이후, 5 월에는 양강 도 남사동에서 채집을 시도하였다. 6월-7월은 함경남도 북청에서 채집 기록이 있다. 7 월 초에는 양강도 갑산군의 보흥리, 여수평, 통남면을 거쳐 포태산까지 채집을 하였 다. 7 월 말에는 혜산진에서 백두산 지역으로 이동하여 8 월 중순까지 무두봉, 무봉, 유평과 설령 채집 기록이 있다. 8 월 중순에는 다시 갑산군 진천보로 돌아온 기록이 남아 있다. 이후 8월말에서 9월말까지 자강도 남사동, 희천에 서 채집을 시도하였다.

4. Nomura, Naohiko (野村直彦): 1926년부터 1936년까지 채집한 532개의 표본들이 교토대학(京都大學)과 일본 국 립과학박물관에 소장되어 있으며, 1926년부터 1932년에 채집된 표본은 28 개로 함경남도 풍산군, 함흥시에서 채집 된 것이고, 대부분의 표본은 1934년과 1935년도에 채집한 것으로 381 개가 된다. 이들 표본은 대부분 함경남도 함흥 고등학교 교사로 재직 시 함흥지역을 중심으로 채집한 것 이다. Numura가 채집한 표본은 대부분 초본으로 목본식물 표본은 42 분류군 48 개에 불과하다(Appendix 4 참조).

[1933년]

6월과 7월 함흥시 반룡산에서 채집한 표본이 있으며, 8 월 13-14일에는 강원도 안녕군 위익면 삼방, 9월 17일 함 주군 동천면 풍서리-풍양리, 10 월 16 일 서호진 등대에서 채집한 표본들이 있다.

[1934년]

4월 16 일부터 함흥시 반룡산, 서상리 등을 채집하고, 7
월 24일-26일 동상면 함대리-부전리, 차일봉의 채집 기록 이 있다. 8 월 15 일-17일 장진군 신각면 북산과 부감리에 서 채집한 표본이 있다.

[1935]

4월 5 일부터 채집한 기록이 있으며, 4 월 28 일에는 함주 군 하산우천면-삼거의 채집기록과 6 월 9일 평안남도 영원 군 황초령, 7월 23일-29일 함경남도 변천보, 대한대리, 부 전군 한대리, 허어수리, 동하면 운산리 등에서 채집을 하 였다.

\section{[1936년]}

6 월 9일 평안남도 영원군에서 채집을 하고, 10 월 10 일 함흥의 반룡산이 마지막 채집 기록이 된다.

5. Saito Tatsumoto (斎藤龍本): 1931년부터 1942년까지 의 1730 개에 대한 기록이 남아 있지만, 1932년부터 1938년 까지 7 년 간 채집한 표본이 1,586 개로 대부분을 차지한다. Saito에 대한 기록은 Kitamura(1977)에 의해 비교적 자세하 게 정리되어 있다. 1930년에 교토대학의 Ohwi와 Kitamura 가 함경도 방문을 하였을 때 채집 방법을 배워 1932년부터 활발한 채집을 시작하였다. 당시 1935년 5월까지는 약사 로 활동하였다.

이후에는 1939년까지는 임산과, 위생과, 상공과, 학무 과에서 근무하면서 채집을 시도하였다. 1939년에서 1941년 3년 간 함경북도 임업시험장과 함경북도 산림회 촉탁 겸무를 맡은 시기에 채집을 중단하였다가 1942년 에 함경북도 과학교육재단과 과학박물관, 만주국 간도 성, 조선군 육군창고 업무를 맡은 시기인 1년 중 여름인 7-8월에 백두산, 그리고 10 월의 청진 채집 기록이 남아 있다. Saito의 표본은 교토대학 표본관(KYO)에 대부분 소장되어 있다(Appendix 5 참조).

\section{[1931년]}

6월 함경북도 청진군 나남과 8 월 경성군의 관모봉에서 의 기록이 있지만 표본수는 10 여 개의 극소량이다.

\section{[1932년]}

본격적으로 채집을 시작한 해로서 5 월부터 표본 채집 을 시도하였다. 주로 함경북도 청진군 나남지역을 채집 하였다. 함경북도 경성 부근의 지역인 남하석산, 관모봉, 나남과 청진 지역인 도정산 지역에서의 채집기록이 남 아있다.

\section{[1933년]}

4-6월 사이에 대부분 나남 지역에서 채집된 기록들이 며, 7월 말에 관모봉, 백두산에서 채집기록이 있다. 9월에 다시 관모봉 채집을 시도하였다. 
Table 1. The following contains gazetteers originally cited in literatures by Japanese taxonomists. The local names are listed in alphabetical order.

\begin{tabular}{|c|c|}
\hline Gazetteer & Collector \\
\hline Anjyu(安州) & Mills,R.G. \\
\hline Banryusan(盤龍山) & Nomura, N. \\
\hline Botandai(牡丹台) & Imai, $\mathrm{H}$ \\
\hline Chang-syong(昌城) & Imai, $\mathrm{H}$ \\
\hline Chimampo(鎭南浦) & Imai, $\mathrm{H}$ \\
\hline Chinnampo(鎭南浦) & Imai, $\mathrm{H}$ \\
\hline Chosan(楚山) & Mills,R.G. \\
\hline Daitaku(大澤) & Saito, T. \\
\hline Engan(延岩) & Furumi, M \\
\hline Fusan(釜山) & Mills,R.G. \\
\hline Genkori & Nomura, N. \\
\hline Gishu(義州) & Imai, $\mathrm{H}$ \\
\hline Gosompo(梧村堡) & Saito, T. \\
\hline Gosui(合水) & Furumi, M \\
\hline $\begin{array}{c}\text { HanSanmonastery } \\
\text { (香山普賢寺) }\end{array}$ & Mills,R.G. \\
\hline Han-san(香山) & Mills,R.G. \\
\hline Heijyo(本壤) & Imai, $\mathrm{H}$ \\
\hline Heizyo(平壤) & Imai, $\mathrm{H}$ \\
\hline Hokkanzan(北漢山) & Mills,R.G. \\
\hline Hokori(保興里) & Furumi, M \\
\hline Hoktan(碧潼) & Mills,R.G. \\
\hline Hosairi(豊西里) & Nomura, N. \\
\hline Hoseiri(豊西里) & Nomura, N. \\
\hline Hotaisan(胞胎山) & Furumi, M \\
\hline Hotaizan(胞胎山) & Furumi, M \\
\hline Igen(渭原) & Imai, $\mathrm{H}$ \\
\hline Jun-an(順安) & Imai, $\mathrm{H}$ \\
\hline Jun-an(楚山) & Imai, $\mathrm{H}$ \\
\hline Jyosuihei(汝水坪) & Furumi, M \\
\hline KaiAwGaiPass(筐地) & Mills,R.G. \\
\hline Kai-syong(价川) & Imai, $\mathrm{H}$ \\
\hline Kangei(江界) & Mills,R.G. \\
\hline Kanggei(江界) & Mills,R.G. \\
\hline Kang-gei(江界) & Mills,R.G. \\
\hline Kangkai(江界) & Mills,R.G. \\
\hline Keijyo(Seoul) & Imai, $\mathrm{H}$ \\
\hline
\end{tabular}

Table 1. Continued.

\begin{tabular}{|c|c|c|c|}
\hline Gazetteer & Collector & Gazetteer & Collector \\
\hline Keizanchin(惠山鎭) & Furumi, M & PyukTang(碧潼) & Mills,R.G. \\
\hline Kokai(江界) & Furumi, M & $\begin{array}{l}\text { QuangCheePahWee } \\
\text { (筐地) }\end{array}$ & Mills,R.G. \\
\hline Kokai(江界) & Mills,R.G. & Ranan(羅南) & \\
\hline Kosho(渭原) & Imai, $\mathrm{H}$ & & Saito, T. \\
\hline Kosuiin(黃水院) & Furumi, M & Ryugakusan(龍岳山) & Imai, $\mathrm{H}$ \\
\hline Ko-sui-in(黃水院 ) & Furumi, M & Ryuko(龍岡) & Imai, $\mathrm{H}$ \\
\hline Kotiri(龍林面厚地洞) & Furumi, M & Sak-jyu(朔州) & Imai, $\mathrm{H}$ \\
\hline Kozanchin(高山鎭) & Imai, $\mathrm{H}$ & Sakushu(傽州) & Imai, $\mathrm{H}$ \\
\hline Kumiho(九味浦) & Imai, $\mathrm{H}$ & SeechunTang(時中洞) & Mills,R.G. \\
\hline Kyojo(鏡城) & Saito, T. & Seechun-dong(時中洞) & Mills,R.G. \\
\hline Kyuryuri(九龍里) & Nomura, N. & See-Tyun-Tang(時中洞) & Mills,R.G. \\
\hline $\begin{array}{l}\text { Minami-Hotaizan } \\
\text { (南胞胎山) }\end{array}$ & Furumi, M & $\begin{array}{l}\text { Seijori(西上里) } \\
\text { Seoul }\end{array}$ & $\begin{array}{l}\text { Nomura, N. } \\
\text { Mills,R.G. }\end{array}$ \\
\hline Moho(茂峯) & Furumi, M & Seuseu(前川) & Mills,R.G. \\
\hline Mosan(茂山) & Furumi, M & SeuTang(瑞東) & Mills,R.G. \\
\hline Mozan(茂山) & Furumi, M & Shuchimen(朱地面) & Nomura, N. \\
\hline Muranbon(牧丹峯) & Imai, $\mathrm{H}$ & Shuhoku(朱北) & Saito, T. \\
\hline Muranbong(牡丹台) & Imai, $\mathrm{H}$ & Shyo-zyo(昌城) & Imai, $\mathrm{H}$ \\
\hline $\begin{array}{l}\text { Myun-Moun-Tang } \\
\text { (明文洞) }\end{array}$ & Mills,R.G. & $\begin{array}{l}\text { SinAnJu(新安州) } \\
\text { Singishu(新義州) }\end{array}$ & Furumi, M \\
\hline Nanshadoko(南社洞) & Furumi, M & Sosan(楚山) & Imai, $\mathrm{H}$ \\
\hline $\begin{array}{l}\text { Nansha-Makunaido } \\
\text { (南社莫內里) }\end{array}$ & Furumi, M & So-san(楚山) & Imai, $\mathrm{H}$ \\
\hline Neihen(寧邊) & Imai, $\mathrm{H}$ & Sozan(甑山) & Saito, T. \\
\hline Nei-hen(寧邊) & Imai, $\mathrm{H}$ & Syong-la-san(松羅山) & Imai, $\mathrm{H}$ \\
\hline Neiyen(㗬邊) & Saito $\mathrm{T}$ & Taidong-gang(大同江) & Imai, $\mathrm{H}$ \\
\hline Nojido(農事洞) & Furumi, M & $\begin{array}{l}\text { Taiseizan, Taiseisan( } \\
\text { 大聖山) }\end{array}$ & Imai, $\mathrm{H}$ \\
\hline Nozido(農事洞) & Furumi, M & Tinnampo(鎭南浦) & Imai, H \\
\hline Otsumitsudai(乙密台) & Imai, $\mathrm{H}$ & Toseizan(渡正山) & Saito, T. \\
\hline Otsumitsudai(乙密台) & Imai, $\mathrm{H}$ & Tosenmen(東川面) & Nomura, N. \\
\hline Paik-tok-ryoeng(柏德嶺) & Furumi, M & Tosuike(東溪水) & Furumi, M \\
\hline Phyongyang(本壤) & Imai, $\mathrm{H}$ & Unnanmen(雪南面) & Nomura, N. \\
\hline Phyng-yang(平壤) & Imai, $\mathrm{H}$ & Unsan(雲山) & Imai, $\mathrm{H}$ \\
\hline Pipalton(飛潑島) & Imai, $\mathrm{H}$ & Unzan(雲山) & Imai, $\mathrm{H}$ \\
\hline Potonkan(普通江) & Imai, $\mathrm{H}$ & WheeChun(熙川) & Mills,R.G. \\
\hline Pyeng-yang(平壤) & Mills,R.G. & Wolgok(月串) & Mills,R.G. \\
\hline Pyeng-yang(平壤) & Imai, $\mathrm{H}$ & Yuhei(榆坪) & Furumi, M \\
\hline Pyok-dong(碧潼) & Imai, $\mathrm{H}$ & Zyu-nan(順安) & Imai, $\mathrm{H}$ \\
\hline
\end{tabular}

Table 1. Continued. 
[1934년]

5-8월까지 주로 나남 지역 채집이 간헐적으로 되어 있지 만, 5 월 29일에서 6 월 5 일까지 주을, 관모봉 조사가 있다.

\section{[1935년]}

3-9월까지 주로 나남과 경성 주변의 채집 기록이 남아 있다.

[1936년]

6월 5-16일 사이에 관모봉, 7월 초에 경성군 지역 조사와 8 월에는 무산과 부령 지역 조사를 시도해서 나남 지역 조 사 이외에 보다 함경북도 많은 지역 조사를 시도하였다.

[1937년]

5 월부터 성진(김책), 서수라, 라진, 백암 지역, 온성 지역 을 채집하였다.

[1938년]

함경북도의 북쪽인 무산-행영, 증산과 송진산 등을 5 월 말과 6 월 중순에서 7 월 중순에 시도하였고, 10 월에는 명 천 지역 조사를 실시하였다. 이 해는 나남보다는 다른 지 역 조사를 시도한 해였다.

[1942년]

3 년 간(39년-41년) 채집기록이 없다가, 42년에 7월 20일 에서 8월 2일까지 백두산 채집기록이 있으며 10월 5-6일 사이 청진 고미산 채집이 있었다.

6. Okuyama Shunki (Syunki) (奥山春李): 31세인 1940년 에 510 여 개의 표본채집을 시도하였다. 강원도와 함경남 도 지역을 약 10 일 간 채집한 기록이다(Appendix 6 참조).

\section{[1940년]}

8월 7일-9일까지 3일 동안 강원도 금강산의 내금강 지 역을 주로 채집한 후 11 일에 함경남도 함흥 채집이 있다. 8 월 14일-16일까지 3일간 부전고원 한대리, 운수령 지역, 차일봉 지역 채집을 시도하였다. 이후 8월 17일에 함흥 서 호진의 채집 기록이 남아 있다.

전체 6명의 채집 표본수는 약 4,700여개로 Nakai의 14,000 여개 기록, Komarov의 7,000여개, Ohwi의 4,300여 개, Faurie와 Taquet의 9,000개의 채집품에 비해서는 비교 적 적은 채집기록이지만, 황해남북도, 평안남북도, 양강 도와 자강도, 함경남북도에 걸친 북한의 채집기록이 많 지 않은 지역의 채집으로서 매우 중요한 분류학적 사적 기록이 된다.

Nakai 문헌에 인용된 표본은 R.G. Mills, H. Imai, M. Furumi로서 해당되는 지명에 대해서는 Table 1에 제시하 였다. Saito의 표본은 주로 Ohwi의 문헌에 언급되었다. 반 면, S. Okuyama, N. Nomura의 표본은 양이 적어 문헌에 인 용된 빈도는 매우 낮다. Mills, Imai, Furumi는 주로 도쿄대
학(TI)에 소장되어 있으며, Nomura와 Saito는 교토대학 (KYO)에, Okuyama는 국립과학박물관(TNS)에 소장되어 있다.

기준표본으로 인용된 빈도는 Imai가 35개, Furumi가 19 개, Mills가 15 개, 그리고 Saito는 7개로 전체 76 개로서 전체 기준표본 정리의 약 $2 \%$ 정도가 된다.

\section{사 사}

본 연구는 산림청 '산림과학기술개발사업(과제번호: S121212L020100, 세부과제번호: S121212L020110)' 20142015년 북한생물다양성(식물) DB 구축의 종발생자료 지 역 정리 부분에 대한 결과물이다.

\section{Literature Cited}

Boufford, D., K. Susan and R. Ree. 2013. Biodiversity of the Hengduan Mountains. Retrieved Sep. 10, 2015, from http:// hengduan.huh.harvard.edu/fieldnotes/gazetteer

BRAHMS. 2015. Botanical Research and Herbarium Management System. Retrieved Sep. 10, 2015, from http://herbaria.plants.ox.ac.uk/bol

Chang, C. S. and G. S. Chang. 2003. Reexamination on V. L. Komarov's collection sites in North Korea - mainly based on Flora Manshuriae. Korean Journal of Plant Taxonomy 33: 203-218. (in Korean)

Chang, C. S. and B. H. Choi. 2004. Reexamination on V. L. Komarov's collection sites in North Korea (II) - mainly based on Nakai's Flora Koreana vol. II. Korean Journal of Plant Taxonomy 33: 203-218. (in Korean)

Chang, C. S., B. H. Choi, H. Kim and J. Y. Lee. 2004. Reexamination on foreign collector's sites and exploration routes in Korea - with respect to U. Faurie. Korean Journal of Plant Taxonomy 34: 37-41. (in Korean)

Chang, C. S. and K. S. Chang. 2010. Reexamination on foreign collector's sites and exploration routes in Korea (IV). - with respect to T. Ishidoya. Korean Journal of Plant Taxonomy 40: 90-104. (in Korean)

Chang, K.S., S.K. Park, H. Kim, C.S. Chang. 2013. A bibliography of three Japanese plant taxonomists (G. Koidzumi, J. Ohwi, and S. Kitamura) of Kyoto University in Korea during 1930s and gazetteer. Korean Journal of Plant Taxonomy 43: 319-331. (in Korean)

Chang, C, S., H. Kim, and K.S. Chang. 2015. Botanical Gazetteer for Korean Peninsular Flora (KPF). Desingpost, Goyang city. (in Korean)

Feeley, K. J. and M. R. Silman. 2011. Keep collecting: accurate species distribution modelling requires more collections than 
previously thought. Diversity and Distributions 17: 11321140.

GBIF. 2011. Global biodiversity information facility. (December 14). Retrieved from http://www.gbif.org

Haripersaud, P., H. Steege., J. J. Granville, H. Chevillotte and M. Hoff. 2010. Species abundance, distribution and diversity in time and space after centuries of botanical collecting in the Guianas. Taxon 59: 592-297.

Harvard University Herbaria \& Librairies. 2015 (December 14). Collections, from http://kiki.huh.harvard.edu/databases/ botanist_search.php?mode $=$ details\&id $=44879$

Hijmans, R. J., L. Guarino and P. Mathur. 2011. DIVA-GIS 7.5. Retrieved Sep. 10, 2012, from http://www.diva-gis.org

Kelly, S. L. 2006. Resolving place names in Amdo and Kham: A gazetteer for the Hengduan Mountains region of Southwest China. Acta Phytotaxonomica Sinica. 44: 721-732.

Kim, H., G. S. Chang, C. S. Chang and B. H. Choi. 2006. Reexamination on foreign collectors' sites and exploration routes in Korea (II) - with respect to T. Nakai. Korean Journal of Plant Taxonomy 36: 227-255. (in Korean)

Kim, H., B. H. Choi, C. S. Chang and K. S. Chang. 2007. Reexamination on foreign collectors' sites and exploration routes in Korea (III) - with respect to T. Uchiyama. Korean Journal of Plant Taxonomy 37: 203-215. (in Korean)

Kim, H., K. S. Chang and C. S. Chang. 2010. E. H. Wilson's expedition to Korea from 1917 to 1919: Resolving place names of his collections. Journal of Japanese Botany 85: 99-117.

Kim, H., K. S. Chang, H. Y. Gil, S. K. Park and C. S. Chang. 2012. T. Mori's collections and resolving place names in
Korea. Korean Journal of Plant Taxonomy 42: 340-353. (in Korean)

Kitamura, S. 1977. A biography of Tatsumoto Saito(1889-1961). Acta Phytotaxonomica et Geobotanica 28: 108-109.

Museum of Vertebrate Zoology and Geospatial Innovation Facility. 2008. Predictive species distribution modeling using tree data. University of California, Berkeley.

Nakai, T. 1912. Plantae Millsianae Koreanae. Bot. Mag. (Tokyo) 26: 29-49.

NGII (National Geographic Information Institute). 2009. Map of Korea. Retrieved Sep. 10, 2015, http://www.ngi.go.kr

Park, Y. H., H. Y. Lee, H. J. No, S. H. Park, J. H. Jeong, G. E. Choi, Y. S. Ham and D. S. Seo. 2002. High school geography Book, Sunggi Culture Co, Seoul. (in Korean)

Pollefeys, P., S. Sharrock and E. Arnaud. 2004. Preliminary analysis of the literature on the distribution of wild Musa species using MGIS and DIVA-GIS. Ministry of International Relations, Quebec.

Sohn, S. W. 1974. Korean geographical dictionary. Kyungin Culture Co., Seoul. (in Korean)

Tang, L., G. Shao, Z. Piao, L. Dai, M. A. Jenkins, S. Wang, G. Wu, J. Wu and J. Zhao. 2010. Forest degradation deepens around and within protected areas in East Asia. Biological Conservation 143: 1295-1298.

The Academy of Korean Studies. 2009. Exemplary uses of old place name. http://www.kostma.net/anArea/anDir.aspx?lang=en

Yeo, I. S. 2004. A history of the research department of the severance union medical college. Korean Journal of Medical History $13: 233-250$. (in Korean) 
Appendix 1. Imai, H.’s itinerary from 1909 to 1912 in P'yongan-namdo and P'yongan-bukto including P'yongyang of North Korea(DPRK).

\begin{tabular}{|c|c|c|c|c|c|c|c|}
\hline Date & Province/City & County & gazetteer & lat & & long & \\
\hline June 22-27, 1909 & P'yongyang & P'yongyang & 平壤 (市街 附近, 大同江岸, 牡丹台, 牧丹峯) & 39.0 & $\mathrm{~N}$ & 125.7 & $\mathrm{E}$ \\
\hline July 2, 1909 & P'yongyang & P'yongyang & 平壤 普通江岸 & 39.0 & $\mathrm{~N}$ & 125.8 & $\mathrm{E}$ \\
\hline Aug. 5, 1909 & P'yongyang & P'yongyang & Pohtongkang 普通江岸 & 39.0 & $\mathrm{~N}$ & 125.8 & $\mathrm{E}$ \\
\hline Aug. 20-25, 1909 & P'yongyang & P'yongyang & $\begin{array}{l}\text { 平壤大同江岸, 牡丹台, 牡丹玄武內外, } \\
\text { 普通江岸, 市街附近, 牧丹臺岩面二着生 }\end{array}$ & 39.0 & $\mathrm{~N}$ & 125.7 & $\mathrm{E}$ \\
\hline Sep 5, 1909 & P'yongyang & P'yongyang & 平壤 普通江岸 & 39.0 & $\mathrm{~N}$ & 125.8 & $\mathrm{E}$ \\
\hline Sep 10, 1909 & P'yongyang & P'yongyang & 平壤 大同江岸 & 39.0 & $\mathrm{~N}$ & 125.7 & $\mathrm{E}$ \\
\hline Sep. 20-26, 1909 & P'yongyang & P'yongyang & 平壤松羅山, 普通江岸, 市街附近, 牡丹台 玄武門外 & 39.0 & $\mathrm{~N}$ & 125.8 & $\mathrm{E}$ \\
\hline Oct 6, 1909 & P'yongan-namdo & Taehung & 黑水洞 & 40.1 & $\mathrm{~N}$ & 127.1 & $\mathrm{E}$ \\
\hline Oct 10,1909 & P'yongyang & P'yongyang & 本壤普通江岸 & 39.0 & $\mathrm{~N}$ & 125.8 & $\mathrm{E}$ \\
\hline Apr. 17,1910 & P'yongyang & P'yongyang & P'yongyang (平壤) & 39.0 & $\mathrm{~N}$ & 125.8 & E \\
\hline Apr. 25,1910 & P'yongyang & P'yongyang & 平壤 乙密臺 & 39.0 & $\mathrm{~N}$ & 125.8 & $\mathrm{E}$ \\
\hline May 1,1910 & P'yongyang & P'yongyang & 平壤 普通江岸, 平壤 牡丹台 & 39.0 & $\mathrm{~N}$ & 125.8 & $\mathrm{E}$ \\
\hline May 8, 1910 & P'yongyang & P'yongyang & 平壤(Otsumitsudai(乙密台), 牡丹台, 大同江岸) & 39.0 & $\mathrm{~N}$ & 125.8 & $\mathrm{E}$ \\
\hline May $14-15,1910$ & P'yongyang & P'yongyang & $\begin{array}{l}\text { RaraPohtongkang普通江, } \\
\text { 平壤(西北二里,牡丹台, 牡丹台, 近郊, 普通江岸) }\end{array}$ & 39.0 & $\mathrm{~N}$ & 125.8 & $\mathrm{E}$ \\
\hline May 20-26, 1910 & P'yongyang & P'yongyang & 平壤(西北二里, 寺洞(平壤東南二里), 西北二里) & 39.1 & $\mathrm{~N}$ & 125.7 & $\mathrm{E}$ \\
\hline June 12,1910 & P'yongyang & P'yongyang & 平壤 (乙密台, 普通江岸, 牡丹台, 牡丹台) & 39.0 & $\mathrm{~N}$ & 125.8 & $\mathrm{E}$ \\
\hline July $2-3,1910$ & P'yongyang & P'yongyang & 平壤, 平壤乙密台 & 39.0 & $\mathrm{~N}$ & 125.8 & $\mathrm{E}$ \\
\hline July 14, 1910 & P'yongyang & P'yongyang & P'yongyang (平壤) & 39.0 & $\mathrm{~N}$ & 125.8 & $\mathrm{E}$ \\
\hline July $28-29,1910$ & P'yongyang & P'yongyang & 平壤, 平壤 普通江岸 & 39.0 & $\mathrm{~N}$ & 125.8 & $\mathrm{E}$ \\
\hline Aug. 2, 1910 & P'yongyang & P'yongyang & 平壤 乙密臺 & 39.0 & $\mathrm{~N}$ & 125.8 & $\mathrm{E}$ \\
\hline Aug. $13-15,1910$ & P'yongyang & P'yongyang & P'yongyang (本壤) & 39.0 & $\mathrm{~N}$ & 125.8 & $\mathrm{E}$ \\
\hline Aug. 17, 1910 & Nampo & Waudo-guyok & 鎭南浦 飛潑島 & 38.7 & $\mathrm{~N}$ & 125.4 & E \\
\hline Aug. 25, 1910 & P'yongyang & P'yongyang & 平壤 牡丹台 & 39.0 & $\mathrm{~N}$ & 125.8 & $\mathrm{E}$ \\
\hline Sep. 2, 1910 & P'yongyang & P'yongyang & P'yongyang (平壤) & 39.0 & $\mathrm{~N}$ & 125.8 & $\mathrm{E}$ \\
\hline Apr. 25, 1911 & P'yongyang & P'yongyang & P'yongyang (平壤) & 39.0 & $\mathrm{~N}$ & 125.8 & $\mathrm{E}$ \\
\hline May 3-7, 1911 & P'yongan-namdo & Chunghwa & 中和, 平壤, 平壤 附近 & 38.9 & $\mathrm{~N}$ & 125.8 & E \\
\hline May 14, 1911 & P'yongyang & P'yongyang & 平壤 附近 & 39.0 & $\mathrm{~N}$ & 125.8 & $\mathrm{E}$ \\
\hline May 21-31, 1911 & P'yongyang & P'yongyang & P'yongyang (平壤) & 39.0 & $\mathrm{~N}$ & 125.8 & $\mathrm{E}$ \\
\hline June $11-18,1911$ & P'yongyang & P'yongyang & P'yongyang(平壤), Ryugakusan(龍岳山), 平壤 & 39.0 & $\mathrm{~N}$ & 125.6 & $\mathrm{E}$ \\
\hline Aug. 2, 1911 & Hwanghae-namdo & Haeju & 海州港 海岸 & 38.0 & $\mathrm{~N}$ & 125.7 & $\mathrm{E}$ \\
\hline Sep. 10, 1911 & P'yongyang & P'yongyang & P'yongyang (平壤) & 39.0 & $\mathrm{~N}$ & 125.8 & $\mathrm{E}$ \\
\hline Sep. 24, 1911 & P'yongyang & P'yongyang & P'yongyang (平壤) & 39.0 & $\mathrm{~N}$ & 125.8 & $\mathrm{E}$ \\
\hline Oct. 1,1911 & Nampo & Waudo-guyok & Chinnampo (鎭南浦) & 38.7 & $\mathrm{~N}$ & 125.4 & $\mathrm{E}$ \\
\hline Oct. 3, 1911 & P'yongyang & P'yongyang & P'yongyang (平壤) & 39.0 & $\mathrm{~N}$ & 125.8 & $\mathrm{E}$ \\
\hline Oct. 9-10, 1911 & P'yongyang & P'yongyang & P'yongyang (平壤) & 39.0 & $\mathrm{~N}$ & 125.8 & $\mathrm{E}$ \\
\hline Apr. 25-28, 1912 & P'yongyang & P'yongyang & P'yongyang (平壤) & 39.0 & $\mathrm{~N}$ & 125.8 & $\mathrm{E}$ \\
\hline May 5-9, 1912 & P'yongyang & Pyongyang & 本壤, 平壤 晋道 江岸 & 39.0 & $\mathrm{~N}$ & 125.7 & E \\
\hline May 15,1912 & P'yongyang & P'yongyang & P'yongyang (平壤) & 39.0 & $\mathrm{~N}$ & 125.8 & $\mathrm{E}$ \\
\hline May 26, 1912 & P'yongyang & P'yongyang & Taiseizan(大聖山) 平壤 & 39.1 & $\mathrm{~N}$ & 125.9 & $\mathrm{E}$ \\
\hline
\end{tabular}


Appendix 1. Continued.

\begin{tabular}{|c|c|c|c|c|c|c|c|}
\hline Date & Province/City & County & gazetteer & lat & & long & \\
\hline June $6-10,1912$ & P'yongyang & P'yongyang & P'yongyang (平壤), Jun-an (順安) & 39.0 & $\mathrm{~N}$ & 125.8 & $\mathrm{E}$ \\
\hline June $18-19,1912$ & P'yongyang & P'yongyang & P'yongyang (平壤) & 39.0 & $\mathrm{~N}$ & 125.8 & $\mathrm{E}$ \\
\hline June 28, 1912 & P'yongan-namdo & Ryonggang & Ryuko(龍岡) & 38.9 & $\mathrm{~N}$ & 125.4 & E \\
\hline July 10, 1912 & P'yongan-namdo & Daean & 江西 & 38.9 & $\mathrm{~N}$ & 125.5 & $\mathrm{E}$ \\
\hline July 20, 1912 & P'yongan-namdo & Daean & 江西 & 38.9 & $\mathrm{~N}$ & 125.5 & E \\
\hline July 22, 1912 & Nampo & Waudo-guyok & Chinnampo (鎭南浦) & 38.7 & $\mathrm{~N}$ & 125.4 & E \\
\hline July $24-25,1912$ & P'yongan-namdo & Kaech'on & Kai-syong (价川), 鐵山 & 39.7 & $\mathrm{~N}$ & 125.9 & E \\
\hline July $26-27,1912$ & P'yongan-bukto & Nyongbyon & Nei-hen (Neiyen 寧邊) & 39.8 & $\mathrm{~N}$ & 125.8 & E \\
\hline Aug. 3-6, 1912 & P'yongan-bukto & Unsan & Unsan (雲山), 豊場 & 40.1 & $\mathrm{~N}$ & 125.9 & E \\
\hline Aug. 7-8, 1912 & Chagang-do & Ch'osan & Chosan(楚山) & 40.8 & $\mathrm{~N}$ & 125.8 & E \\
\hline Aug. 10, 1912 & Chagang-do & Manp'o & Kozanchin (高山鎭) & 41.1 & $\mathrm{~N}$ & 126.1 & $\mathrm{E}$ \\
\hline Aug. 13, 1912 & Chagang-do & Wiwon & Kosho (渭原) & 40.9 & $\mathrm{~N}$ & 126.0 & $\mathrm{E}$ \\
\hline Aug. 14-15, 1912 & Chagang-do & Ch'osan & Chosan(楚山), 楚山郡 雪傷 & 40.8 & $\mathrm{~N}$ & 125.8 & $\mathrm{E}$ \\
\hline Aug. 15-16, 1912 & P'yongan-bukto & Byokdong & Pyuk Tang (碧潼) & 40.6 & $\mathrm{~N}$ & 125.3 & $\mathrm{E}$ \\
\hline Aug. 17, 1912 & P'yongan-bukto & Ch'angsong & 昌城 昌州 & 40.5 & $\mathrm{~N}$ & 125.2 & $\mathrm{E}$ \\
\hline Au.g 18, 1912 & P'yongan-bukto & Sakju & Sak-jyu (Sakushu 朔州) & 40.4 & $\mathrm{~N}$ & 125.0 & $\mathrm{E}$ \\
\hline Aug. 23-24, 1912 & P'yongan-bukto & Uiju & Gishu(義州) & 40.2 & $\mathrm{~N}$ & 124.5 & E \\
\hline Sep. 6, 1912 & P'yongyang & P'yongyang & P'yongyang (本壤) & 39.0 & $\mathrm{~N}$ & 125.8 & $\mathrm{E}$ \\
\hline Sep. 17, 1912 & P'yongyang & P'yongyang & P'yongyang (本壤) & 39.0 & $\mathrm{~N}$ & 125.8 & E \\
\hline Sep. 28-29, 1912 & P'yongyang & Pyongyang & 平壤 大同江 西, 平壤 寺洞 & 39.0 & $\mathrm{~N}$ & 125.7 & E \\
\hline
\end{tabular}

Appendix 2. Mills, R. G.'s itinerary from 1909 to 1912 in P'yongan-namdo and P'yongan-bukto including P'yongyang of North Korea(DPRK).

\begin{tabular}{|c|c|c|c|c|c|c|c|}
\hline Date & Province/City & County & gazetteer & lat & & long & \\
\hline Apr. 6-10, 1909 & Chagang-do & Kanggye & Kang-gei(Kokai 江界) & 41.0 & $\mathrm{~N}$ & 126.6 & $\mathrm{E}$ \\
\hline May 19-21, 1909 & Chagang-do & Kanggye & Kang-gei(Kokai 江界) & 41.0 & $\mathrm{~N}$ & 126.6 & $\mathrm{E}$ \\
\hline June 10, 1909 & Chagang-do & Kanggye & Kang-gei(Kokai 江界) & 41.0 & $\mathrm{~N}$ & 126.6 & $\mathrm{E}$ \\
\hline June 20, 1909 & Chagang-do & Kanggye & Kang-gei(Kokai 江界) & 41.0 & $\mathrm{~N}$ & 126.6 & $\mathrm{E}$ \\
\hline July 4, 1909 & Chagang-do & Kanggye & Kang-gei(Kokai 江界) & 41.0 & $\mathrm{~N}$ & 126.6 & $\mathrm{E}$ \\
\hline July 16-25, 1909 & Chagang-do & Kanggye & Kang-gei(Kokai 江界) & 41.0 & $\mathrm{~N}$ & 126.6 & $\mathrm{E}$ \\
\hline Aug. 15-18, 1909 & Chagang-do & Chonch'on & Sensen (前川) & 40.6 & $\mathrm{~N}$ & 126.5 & $\mathrm{E}$ \\
\hline Aug. 25-28, 1909 & P'yongyang & P'yongyang & P'yongyang (平壤) & 39.0 & $\mathrm{~N}$ & 125.8 & $\mathrm{E}$ \\
\hline Sep. 5, 1909 & $\begin{array}{c}\text { Seoul, } \\
\text { Gyeonggi-do }\end{array}$ & & Seoul, Syououen(水原) & 37.6 & $\mathrm{~N}$ & 127.0 & $\mathrm{E}$ \\
\hline Oct. 3, 1909 & Chagang-do & Kanggye & Kang-gei(Kokai 江界) & 41.0 & $\mathrm{~N}$ & 126.6 & $\mathrm{E}$ \\
\hline Feb. 8, 1910 & Chagang-do & Kanggye & Kang-gei(Kokai 江界) & 41.0 & $\mathrm{~N}$ & 126.6 & $\mathrm{E}$ \\
\hline Mar. 18, 1910 & Chagang-do & Kanggye & Kang-gei(Kokai 江界) & 41.0 & $\mathrm{~N}$ & 126.6 & $\mathrm{E}$ \\
\hline Apr. 16-24, 1910 & P'yongan-namdo & Anju & $\begin{array}{l}\text { Kai Aw Gai Pass(筐地, 광지 바위), } \\
\text { Anjyu (安州) }\end{array}$ & 39.7 & $\mathrm{~N}$ & 125.8 & $\mathrm{E}$ \\
\hline Apr. 28, 1910 & Chagang-do & Kanggye & Kang-gei(Kokai 江界) & 41.0 & $\mathrm{~N}$ & 126.6 & $\mathrm{E}$ \\
\hline May 6-10, 1910 & Chagang-do & Kanggye & Kang-gei(Kokai 江界) & 41.0 & $\mathrm{~N}$ & 126.6 & $\mathrm{E}$ \\
\hline June 6,1910 & Seoul & Jongro & Hokkanzan (北漢山) & 37.6 & $\mathrm{~N}$ & 127.0 & $\mathrm{E}$ \\
\hline
\end{tabular}


Appendix 2. Continued.

\begin{tabular}{|c|c|c|c|c|c|c|c|}
\hline Date & Province/City & County & gazetteer & lat & & long & \\
\hline June $6-8,1910$ & Chagang-do & Kanggye & Kang-gei(Kokai 江界) & 41.0 & $\mathrm{~N}$ & 126.6 & $\mathrm{E}$ \\
\hline June 20, 1910 & Chagang-do & Kanggye & Kang-gei(Kokai 江界) & 41.0 & $\mathrm{~N}$ & 126.6 & $\mathrm{E}$ \\
\hline July 4, 1910 & Chagang-do & Kanggye & Kang-gei(Kokai 江界) & 41.0 & $\mathrm{~N}$ & 126.6 & $\mathrm{E}$ \\
\hline July $12-16,1910$ & Chagang-do & Kanggye & Kang-gei(Kokai 江界) & 41.0 & $\mathrm{~N}$ & 126.6 & $\mathrm{E}$ \\
\hline July $26-28,1910$ & Chagang-do & Kanggye & Kang-gei(Kokai 江界) & 41.0 & $\mathrm{~N}$ & 126.6 & $\mathrm{E}$ \\
\hline Aug. $1-10,1910$ & Chagang-do & Kanggye & Kang-gei(Kokai 江界) & 41.0 & $\mathrm{~N}$ & 126.6 & $\mathrm{E}$ \\
\hline Aug. 11-12, 1910 & Chagang-do & Sijung & Seechun dong(時中洞), Chosan(楚山) & 41.1 & $\mathrm{~N}$ & 126.4 & $\mathrm{E}$ \\
\hline Aug. 13, 1910 & P'yongan-bukto & Byokdong & Pyuk Tang (碧潼) & 40.6 & $\mathrm{~N}$ & 125.3 & $\mathrm{E}$ \\
\hline Sep. 24, 1910 & P'yongyang & P'yongyang & P'yongyang (平壤) & 39.0 & $\mathrm{~N}$ & 125.8 & E \\
\hline Sep. $27-30,1910$ & P'yongan-namdo & Anju & $\begin{array}{l}\text { Anjyu(安州), SinAnJu(新安州), } \\
\text { KaiAwGaiPass(筐地, 광지 바위) }\end{array}$ & 39.6 & $\mathrm{~N}$ & 125.7 & $\mathrm{E}$ \\
\hline Sep. 30, 1910 & P'yongan-bukto & Pakch'on & Seu Tang(瑞東)兩嘉面 & 39.7 & $\mathrm{~N}$ & 125.6 & $\mathrm{E}$ \\
\hline Oct. $1-2,1910$ & P'yongan-bukto & $\begin{array}{l}\text { Hyangsan, } \\
\text { Pakch'on }\end{array}$ & $\begin{array}{l}\text { HanSanmonastery(香山普賢寺), } \\
\text { SeuTang(瑞東)兩嘉面 }\end{array}$ & 40.0 & $\mathrm{~N}$ & 126.2 & $\mathrm{E}$ \\
\hline Oct. 3-4, 1910 & Chagang-do & Huich'on & $\begin{array}{l}\text { Whee Chun(熙川), 熙川郡 北面 (明 } \\
\text { 文洞) }\end{array}$ & 40.2 & $\mathrm{~N}$ & 126.3 & E \\
\hline Oct. 5-8, 1910 & Chagang-do & Kanggye & Kang-gei(Kokai 江界) & 41.0 & $\mathrm{~N}$ & 126.6 & $\mathrm{E}$ \\
\hline Oct. 15,1910 & Chagang-do & Kanggye & Kang-gei(Kokai 江界) & 41.0 & $\mathrm{~N}$ & 126.6 & $\mathrm{E}$ \\
\hline Nov. 25, 1910 & Chagang-do & Kanggye & Kang-gei(Kokai 江界) & 41.0 & $\mathrm{~N}$ & 126.6 & $\mathrm{E}$ \\
\hline Mar. 4, 1911 & Chagang-do & Kanggye & Kang-gei(Kokai 江界) & 41.0 & $\mathrm{~N}$ & 126.6 & $\mathrm{E}$ \\
\hline Apr. 0-5, 1911 & Chagang-do & Kanggye & Kang-gei(Kokai 江界) & 41.0 & $\mathrm{~N}$ & 126.6 & $\mathrm{E}$ \\
\hline Apr. 15, 1911 & Chagang-do & Kanggye & Kang-gei(Kokai 江界) & 41.0 & $\mathrm{~N}$ & 126.6 & $\mathrm{E}$ \\
\hline Apr. 25-29, 1911 & Chagang-do & Kanggye & Kang-gei(Kokai 江界) & 41.0 & $\mathrm{~N}$ & 126.6 & $\mathrm{E}$ \\
\hline Apr. 28-29, 1911 & Chagang-do & Kanggye & Kang-gei(Kokai 江界) & 41.0 & $\mathrm{~N}$ & 126.6 & $\mathrm{E}$ \\
\hline May 6-13, 1911 & Chagang-do & Kanggye & Kang-gei(Kokai 江界) & 41.0 & $\mathrm{~N}$ & 126.6 & E \\
\hline May 20-25, 1911 & Chagang-do & Kanggye & Kang-gei(Kokai 江界) & 41.0 & $\mathrm{~N}$ & 126.6 & $\mathrm{E}$ \\
\hline June, 1911 & Chagang-do & Kanggye & Kang-gei(Kokai 江界) & 41.0 & $\mathrm{~N}$ & 126.6 & E \\
\hline June 1-5, 1911 & Chagang-do & Kanggye & Kang-gei(Kokai 江界) & 41.0 & $\mathrm{~N}$ & 126.6 & $\mathrm{E}$ \\
\hline June $10-15,1911$ & Chagang-do & Kanggye & Kang-gei(Kokai 江界) & 41.0 & $\mathrm{~N}$ & 126.6 & $\mathrm{E}$ \\
\hline June $20-30,1911$ & Chagang-do & Kanggye & Kang-gei(Kokai 江界) & 41.0 & $\mathrm{~N}$ & 126.6 & $\mathrm{E}$ \\
\hline July 1-9, 1911 & Chagang-do & Kanggye & Kang-gei(Kokai 江界) & 41.0 & $\mathrm{~N}$ & 126.6 & $\mathrm{E}$ \\
\hline July $15-20,1911$ & Chagang-do & Kanggye & Kang-gei(Kokai 江界) & 41.0 & $\mathrm{~N}$ & 126.6 & E \\
\hline July 25-30, 1911 & Chagang-do & Kanggye & Kang-gei(Kokai 江界) & 41.0 & $\mathrm{~N}$ & 126.6 & $\mathrm{E}$ \\
\hline Aug. 1-7, 1911 & Chagang-do & Kanggye & Kang-gei(Kokai 江界) & 41.0 & $\mathrm{~N}$ & 126.6 & E \\
\hline Aug 10-19, 1911 & Chagang-do & Kanggye & Kang-gei(Kokai 江界) & 41.0 & $\mathrm{~N}$ & 126.6 & $\mathrm{E}$ \\
\hline Aug. 24, 1911 & Chagang-do & $\begin{array}{l}\text { Sijung, Wiwon, } \\
\text { Ch'osan }\end{array}$ & $\begin{array}{l}\text { Seechundong(時中洞), } \\
\text { WeeWon(渭原)KooUbe,MangKang }\end{array}$ & 41.1 & $\mathrm{~N}$ & 126.4 & $\mathrm{E}$ \\
\hline Aug. 25, 1911 & P'yongan-bukto & Ch'angsong, Sakju & Chang Sung (昌城), Sakju (朔州) & 40.5 & $\mathrm{~N}$ & 125.2 & $\mathrm{E}$ \\
\hline Aug. 30, 1911 & Chagang-do & Chonch'on & Sensen (前川) & 40.6 & $\mathrm{~N}$ & 126.5 & $\mathrm{E}$ \\
\hline Sep. 15,1911 & Seoul & & Seoul & 37.6 & $\mathrm{~N}$ & 127.0 & $\mathrm{E}$ \\
\hline Oct. 25,1911 & Busan & & 釜山 & 35.2 & $\mathrm{~N}$ & 129.1 & $\mathrm{E}$ \\
\hline Mar.31,1912 & Busan & & 釜山 & 35.2 & $\mathrm{~N}$ & 129.1 & $\mathrm{E}$ \\
\hline Apr. 19-22, 1912 & Busan & & 釜山 & 35.2 & $\mathrm{~N}$ & 129.1 & E \\
\hline
\end{tabular}


Appendix 2. Continued.

\begin{tabular}{|c|c|c|c|c|c|c|c|}
\hline Date & Province/City & County & gazetteer & lat & & long & \\
\hline Apr. 22, 1912 & Busan & & 釜山 & 35.2 & $\mathrm{~N}$ & 129.1 & $\mathrm{E}$ \\
\hline Apr. 29, 1912 & Busan & & 釜山 & 35.2 & $\mathrm{~N}$ & 129.1 & $\mathrm{E}$ \\
\hline Nov. 29, 1913 & Seoul & & Seoul & 37.6 & $\mathrm{~N}$ & 127.0 & $\mathrm{E}$ \\
\hline Apr. 16-28, 1914 & Seoul & & Seoul & 37.6 & $\mathrm{~N}$ & 127.0 & $\mathrm{E}$ \\
\hline May 1-9, 1914 & Seoul & & Seoul, Puck Han & 37.6 & $\mathrm{~N}$ & 127.0 & $\mathrm{E}$ \\
\hline May $15-25,1914$ & Seoul & Jongro & Puck Han, Hokkanzan (北漢山) & 37.7 & $\mathrm{~N}$ & 127.0 & $\mathrm{E}$ \\
\hline June 5-6, 1914 & Seoul & & Seoul & 37.6 & $\mathrm{~N}$ & 127.0 & $\mathrm{E}$ \\
\hline June $13-19,1914$ & Seoul & & Seoul & 37.6 & $\mathrm{~N}$ & 127.0 & $\mathrm{E}$ \\
\hline July 8-9, 1914 & Gyeonggi-do & Yeoncheon & Wolgok(月串) Dongsan & 38.0 & $\mathrm{~N}$ & 127.0 & $\mathrm{E}$ \\
\hline June $29-30,1921$ & Hwanghae-namdo & Ryongyon & $\begin{array}{l}\text { 九味浦, 龍淵郡 九味浦, } \\
\text { 長淵郡 九味浦 (Sorai beach) }\end{array}$ & 38.1 & $\mathrm{~N}$ & 125.0 & $\mathrm{E}$ \\
\hline July $1-29,1921$ & Hwanghae-namdo & Ryongyon & 九味浦 & 38.1 & $\mathrm{~N}$ & 125.0 & $\mathrm{E}$ \\
\hline Aug. 2-7, 1921 & Hwanghae-namdo & Ryongyon & 九味浦 & 38.1 & $\mathrm{~N}$ & 125.0 & $\mathrm{E}$ \\
\hline June $26-29,1922$ & Hwanghae-namdo & Ryongyon & 九味浦 & 38.1 & $\mathrm{~N}$ & 125.0 & $\mathrm{E}$ \\
\hline July 4, 1922 & Hwanghae-namdo & Ryongyon & 九味浦 & 38.1 & $\mathrm{~N}$ & 125.0 & $\mathrm{E}$ \\
\hline July 14-24, 1922 & Hwanghae-namdo & Ryongyon & 九味浦, 夢金浦, Mukimpo & 38.1 & $\mathrm{~N}$ & 125.0 & $\mathrm{E}$ \\
\hline Aug. 10, 1922 & Kaesong & Panmun & Myo Daug & 37.9 & $\mathrm{~N}$ & 126.6 & $\mathrm{E}$ \\
\hline
\end{tabular}

Appendix 3. Furumi, M.'s itinerary for the 1917 from Sinuiju to Hamgyong-namdo of North Korea(DPRK).

\begin{tabular}{|c|c|c|c|c|c|c|c|}
\hline Date & Province/City & County & gazetteer & lat & & long & \\
\hline Apr. 5, 1917 & Sinuiju & Sinuiju & 鴨綠江 & 40.1 & $\mathrm{~N}$ & 124.4 & $\mathrm{E}$ \\
\hline Apr. $14-30,1917$ & Sinuiju & Sinuiju & 新義州 & 40.1 & $\mathrm{~N}$ & 124.3 & $\mathrm{E}$ \\
\hline May 4-June 18, 1917 & Ryanggang & Kimhyongjik & 東興面 南社洞 & 41.2 & $\mathrm{~N}$ & 127.2 & $\mathrm{E}$ \\
\hline June 21-25, 1917 & Hamgyong-namdo & Doksong & 北靑-直洞- - 豊山 新豊里- 甲山 -上里-鷹德峯- & 40.5 & $\mathrm{~N}$ & 128.2 & $\mathrm{E}$ \\
\hline June 23-June 25, 1917 & Ryanggang & Kimhyonggwon & 厚峙嶺, 黃水院里, 新豊里, 甲山 -上里, 鷹德峯 & 40.6 & $\mathrm{~N}$ & 128.2 & $\mathrm{E}$ \\
\hline July $1-3,1917$ & Ryanggang & Poch'on & 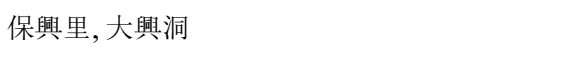 & 41.5 & $\mathrm{~N}$ & 128.4 & $\mathrm{E}$ \\
\hline July 6-7, 1917 & Ryanggang & Poch'on & 汝水坪, 通南面 (南坪里), 甲山- 合水 & 41.5 & $\mathrm{~N}$ & 128.5 & $\mathrm{E}$ \\
\hline July $10-12,1917$ & Ryanggang & Samjiyon & 胞胎山- 南胞胎山- 雪嶺雪嶺 山頂, 寶泰洞 & 41.8 & $\mathrm{~N}$ & 128.4 & $\mathrm{E}$ \\
\hline July 21-22, 1917 & Ryanggang & Samjiyon & 白頭山 & 41.9 & $\mathrm{~N}$ & 128.0 & $\mathrm{E}$ \\
\hline July 24-28, 1917 & Ryanggang & Hyesan & 惠山鎭- 普天堡- 鷹德岺 - 合水 - 寶泰洞 - 虛項嶺 & 41.3 & $\mathrm{~N}$ & 128.1 & $\mathrm{E}$ \\
\hline July 29-31, 1917 & Ryanggang & Samjiyon & 三池淵 -神武城- 虛項嶺- 無頭峯-白頭山 & 41.8 & $\mathrm{~N}$ & 128.3 & $\mathrm{E}$ \\
\hline Aug. 2-3, 1917 & Ryanggang & Taehongdan & 茂峯- 農事洞- 白頭山, 鷹洞 & 41.9 & $\mathrm{~N}$ & 128.7 & $\mathrm{E}$ \\
\hline Aug. 6-9. 1917 & Ryanggang & Paegam & 延岩-西溪水-東溪水 & 41.2 & $\mathrm{~N}$ & 128.7 & $\mathrm{E}$ \\
\hline Aug. 11-14. 1917 & Ryanggang & Taehongdan & 茂峯- 農事洞, 明花洞-普天堡 -柏德嶺 & 41.9 & $\mathrm{~N}$ & 128.7 & $\mathrm{E}$ \\
\hline Aug. 21-25, 1917 & Hamgyong-bukto & Yonsa & 鷹洞,南社 莫內里, 雪嶺 & 41.9 & $\mathrm{~N}$ & 128.9 & $\mathrm{E}$ \\
\hline Aug. 26-27, 1917 & Ryanggang & Kimhyongjik & 南社洞 水源地 周峯頂 & 41.4 & $\mathrm{~N}$ & 126.8 & $\mathrm{E}$ \\
\hline Aug. 30-Sep. 5, 1917 & Ryanggang & Kimhyongjik & 周峯頂-頭雲峯-南社洞-五佳山 & 41.2 & $\mathrm{~N}$ & 127.2 & $\mathrm{E}$ \\
\hline Sep. 20-21, 1917 & Chagang-do & Ryongrim & 龍林面 厚地洞 & 40.6 & $\mathrm{~N}$ & 126.8 & $\mathrm{E}$ \\
\hline Sep. 25-26, 1917 & Chagang-do & Tongsin & 熙川郡 西洞 & 40.2 & $\mathrm{~N}$ & 126.6 & $\mathrm{E}$ \\
\hline
\end{tabular}


Appendix 4. Nomura's itinerary from 1930 to 1936 in Hamgyong-namdo of North Korea(DPRK).

\begin{tabular}{|c|c|c|c|c|c|c|c|}
\hline Date & Province/City & County & gazetter & lat. & & long. & \\
\hline Apr. 20, 1926 & Ryanggang & Kimhyonggwon & 豊山郡 豊山 & 40.8 & $\mathrm{~N}$ & 128.2 & E \\
\hline $05-23,1930$ & Hamgyong-namdo & Hamhung & 咸興. 盤龍山 & 39.9 & $\mathrm{~N}$ & 127.5 & $\mathrm{E}$ \\
\hline July 25.1930 & Hamgyong-namdo & Hamhung & $\begin{array}{l}\text { 松興里 磐龍山, 興慶里 兄弟山, 千佛山, } \\
\text { 咸興 歸州寺, 白岩山 }\end{array}$ & 39.9 & $\mathrm{~N}$ & 127.5 & $\mathrm{E}$ \\
\hline $\begin{array}{l}\text { June } 19 \\
\text {-Sep. } 17,1932\end{array}$ & Hamgyong-namdo & Hamhung & $\begin{array}{l}\text { 松興里 磐龍山, 興慶里 兄弟山, } \\
\text { 千佛山, 嵗興 歸州寺, 白岩山 }\end{array}$ & 39.9 & $\mathrm{~N}$ & 127.5 & $\mathrm{E}$ \\
\hline June 12, 1933 & Hamgyong-namdo & Hamhung & 咸興 盤龍山 & 39.9 & $\mathrm{~N}$ & 127.5 & $\mathrm{E}$ \\
\hline Aug. 13-14, 1933 & Kangwon-do & Sep'o & 安邊郡 衞䀂面 三防 & 38.8 & $\mathrm{~N}$ & 127.4 & $\mathrm{E}$ \\
\hline Aug. 24-29, 1933 & Hamgyong-namdo & Hamhung & 咸興 盤龍山, 下岐川面 下東興里, 麥田山 & 39.9 & $\mathrm{~N}$ & 127.5 & $\mathrm{E}$ \\
\hline Sep. 10-24, 1933 & Hamgyong-namdo & Hamhung & $\begin{array}{l}\text { 咸興 松興谷 盤龍山, 東川面 豊陽里 牡洞峠, } \\
\text { 興慶里 兄弟山, 豊西里, 豊陽里, 牡洞峠, 興慶里 }\end{array}$ & 39.9 & $\mathrm{~N}$ & 127.5 & $\mathrm{E}$ \\
\hline Oct. 2, 1933 & Hamgyong-namdo & Hamhung & 咸興 盤龍山 & 39.9 & $\mathrm{~N}$ & 127.5 & $\mathrm{E}$ \\
\hline Oct. 16,1933 & Hamgyong-namdo & Jangjin & 富盛里, 西湖津 燈臺 & 40.3 & $\mathrm{~N}$ & 127.3 & $\mathrm{E}$ \\
\hline Oct. 22,1933 & Hamgyong-namdo & Chongp'yong & 西湖津 & 39.8 & $\mathrm{~N}$ & 127.7 & $\mathrm{E}$ \\
\hline Apr. 16, 1934 & Hamgyong-namdo & Hamhung & 祥興里 磐龍山 & 39.9 & $\mathrm{~N}$ & 127.5 & $\mathrm{E}$ \\
\hline May 5-6, 1934 & Hamgyong-namdo & Hamhung & 咸興 盤龍山 & 39.9 & $\mathrm{~N}$ & 127.5 & $\mathrm{E}$ \\
\hline May $13-18,1934$ & Hamgyong-namdo & Hamhung & 咸興西上里, 咸興城川江岸, 盤龍山 & 39.9 & $\mathrm{~N}$ & 127.5 & $\mathrm{E}$ \\
\hline May 27-29, 1934 & Hamgyong-namdo & Hamhung & 咸興 盤龍山 & 39.9 & $\mathrm{~N}$ & 127.5 & $\mathrm{E}$ \\
\hline June 14, 1934 & Hamgyong-namdo & Hamhung & 咸興 城川江 西上里 堤防 & 39.9 & $\mathrm{~N}$ & 127.5 & $\mathrm{E}$ \\
\hline June $24-27,1934$ & Hamgyong-namdo & Hamhung & 咸興 盤龍山,松興谷 盤龍山 & 39.9 & $\mathrm{~N}$ & 127.5 & $\mathrm{E}$ \\
\hline July 8,1934 & Hamgyong-namdo & Hamhung & 祥興里 磐龍山 & 39.9 & $\mathrm{~N}$ & 127.5 & $\mathrm{E}$ \\
\hline July 8,1934 & Hamgyong-namdo & Hamju & 禪興谷 & 40.2 & $\mathrm{~N}$ & 127.6 & $\mathrm{E}$ \\
\hline July 24-26, 1934 & Hamgyong-namdo & Pujon & 東上面咸地里-赴戰嶺, 東上面遮日峰, 漢岱里 & 40.4 & $\mathrm{~N}$ & 127.6 & $\mathrm{E}$ \\
\hline Aug. 12, 1934 & Hamgyong-namdo & Hongwon & 九龍里 & 40.2 & $\mathrm{~N}$ & 127.8 & $\mathrm{E}$ \\
\hline Aug. 15-17, 1934 & Hamgyong-namdo & Jangjin & 新角面 北山, 富盛里, 長津 中庄洞 & 40.3 & $\mathrm{~N}$ & 127.4 & $\mathrm{E}$ \\
\hline Aug. 18, 1934 & Hamgyong-namdo & Hamhung & 咸興 興西面 & 39.8 & $\mathrm{~N}$ & 127.6 & $\mathrm{E}$ \\
\hline Sep. 11-13, 1934 & Hamgyong-namdo & Hamhung & 咸興 興西面 & 39.8 & $\mathrm{~N}$ & 127.6 & $\mathrm{E}$ \\
\hline Sep. 18,1934 & Hamgyong-namdo & Hamju & 咸州郡 朱北面 興祥 & 40.0 & $\mathrm{~N}$ & 127.4 & $\mathrm{E}$ \\
\hline Sep. 30, 1934 & Hamgyong-namdo & Kumya & 九龍里 & 39.4 & $\mathrm{~N}$ & 127.4 & $\mathrm{E}$ \\
\hline Apr. 5-9, 1935 & Hamgyong-namdo & Hamhung & Hamhung (咸興), 松興谷 盤龍山, 咸興 歸州寺 & 39.9 & $\mathrm{~N}$ & 127.5 & $\mathrm{E}$ \\
\hline Apr. $14-21,1935$ & Hamgyong-namdo & Hamhung & $\begin{array}{l}\text { Hamhung (咸興), 咸興 Rempeijo, } \\
\text { 咸興 校庭 高等普通學校, 咸興 西上面 提防 }\end{array}$ & 39.9 & $\mathrm{~N}$ & 127.5 & $\mathrm{E}$ \\
\hline Apr. 27, 1935 & Hamgyong-namdo & Hamhung & Hamhung (戌興) & 39.9 & $\mathrm{~N}$ & 127.5 & $\mathrm{E}$ \\
\hline Apr. 28, 1935 & Hamgyong-namdo & Hamju & 下岐川面 保庄 - 三巨, 咸州, Kakisen 下岐川面 & 40.2 & $\mathrm{~N}$ & 127.3 & $\mathrm{E}$ \\
\hline Apr. 29, 1935 & Hamgyong-namdo & Hamhung & Hamhung (咸興) & 39.9 & $\mathrm{~N}$ & 127.5 & $\mathrm{E}$ \\
\hline May, 1935 & Hamgyong-namdo & Sudong & 水洞區 竹田里 馳馬臺 & 39.3 & $\mathrm{~N}$ & 127.0 & $\mathrm{E}$ \\
\hline May 5, 1935 & Hamgyong-namdo & Hamhung & Hamhung (咸興) & 39.9 & $\mathrm{~N}$ & 127.5 & $\mathrm{E}$ \\
\hline May 9-10, 1935 & Hamgyong-namdo & Hamhung & 咸興 歸州寺, 瑚連洞 堤坊, 松興谷 盤龍山 & 39.9 & $\mathrm{~N}$ & 127.6 & $\mathrm{E}$ \\
\hline May 19-20, 1935 & Hamgyong-namdo & Hamhung & Hamhung (咸興), 馳馬台, 咸興 校庭 & 39.9 & $\mathrm{~N}$ & 127.5 & $\mathrm{E}$ \\
\hline June 7, 1935 & Hamgyong-namdo & Hamhung & 咸興 校庭 & 39.9 & $\mathrm{~N}$ & 127.6 & $\mathrm{E}$ \\
\hline
\end{tabular}


Appendix 4. Continued.

\begin{tabular}{|c|c|c|c|c|c|c|c|}
\hline Date & Province/City & County & gazetter & lat. & & long. & \\
\hline June 9,1935 & P'yongan-namdo & Nyongwon & 黃草嶺 & 40.3 & $\mathrm{~N}$ & 127.3 & $\mathrm{E}$ \\
\hline June 14,1935 & Hamgyong-namdo & Hamhung & 咸興 西上面 提防 & 39.9 & $\mathrm{~N}$ & 127.5 & E \\
\hline June 23, 1935 & P'yongan-namdo & Nyongwon & 黃草嶺 & 40.3 & $\mathrm{~N}$ & 127.3 & $\mathrm{E}$ \\
\hline June 27, 1935 & Hamgyong-namdo & Hamhung & 松興谷 盤龍山 & 39.9 & $\mathrm{~N}$ & 127.5 & $\mathrm{E}$ \\
\hline July 7,1935 & Hamgyong-namdo & Jangjin & 在院里 & 40.3 & $\mathrm{~N}$ & 127.3 & $\mathrm{E}$ \\
\hline July $23-26,1935$ & Hamgyong-namdo & Pujon & $\begin{array}{l}\text { 東上面漢垈里 湖畔, 蓋馬高原 弁天島, 東下面 把田洞, } \\
\text { 東上面 漢岱里, 西於水里, 東下面 把田洞, 雲山里 }\end{array}$ & 40.7 & $\mathrm{~N}$ & 127.0 & $\mathrm{E}$ \\
\hline July $28-29,1935$ & Hamgyong-namdo & Pujon & 東上面漢袋里 湖畔, 赴戰嶺 & 40.7 & $\mathrm{~N}$ & 127.5 & $\mathrm{E}$ \\
\hline Aug. 3, 1935 & Hamgyong-namdo & Hamju & 咸州郡 朱北面 興祥 & 40.0 & $\mathrm{~N}$ & 127.4 & $\mathrm{E}$ \\
\hline Aug. 7, 1935 & Hamgyong-namdo & Jangjin & 在院里 & 40.3 & $\mathrm{~N}$ & 127.3 & $\mathrm{E}$ \\
\hline Aug. 14,1935 & Hamgyong-namdo & Hamju & 雪南面 營岱里 & 39.9 & $\mathrm{~N}$ & 127.6 & $\mathrm{E}$ \\
\hline Sep. 28,1935 & Hamgyong-namdo & Hamhung & 咸興, 西上里 & 39.9 & $\mathrm{~N}$ & 127.5 & $\mathrm{E}$ \\
\hline Oct. 5, 1935 & Hamgyong-namdo & Hamhung & 咸興 盤龍山 & 39.9 & $\mathrm{~N}$ & 127.5 & E \\
\hline July 27, 1936 & Hamgyong-namdo & Pujon & Tojomen (東上面) & 40.5 & $\mathrm{~N}$ & 127.7 & $\mathrm{E}$ \\
\hline Sep. 4, 1936 & Hamgyong-namdo & Hamju & 下岐川面 三巨, 咸興 盤龍山 & 40.2 & $\mathrm{~N}$ & 127.3 & $\mathrm{E}$ \\
\hline Oct. 10,1936 & Hamgyong-namdo & Hamhung & 咸興 盤龍山 & 39.9 & $\mathrm{~N}$ & 127.5 & $\mathrm{E}$ \\
\hline
\end{tabular}

Appendix 5. Saito, T.'s itinerary from 1929 to 1942 in Hamgyong-bukto and Ryanggang of North Korea(DPRK).

\begin{tabular}{|c|c|c|c|c|c|c|c|}
\hline Date & Province/City & County & gazetter & lat. & & long. & \\
\hline June 24, 1929 & Hamgyong-bukto & Kyongsong & 鏡城 & 42.8 & $\mathrm{~N}$ & 129.8 & $\mathrm{E}$ \\
\hline July 13, 1930 & Hamgyong-bukto & Kyongsong & 鏡城 & 42.8 & $\mathrm{~N}$ & 129.8 & $\mathrm{E}$ \\
\hline June 7-9, 1931 & Hamgyong-bukto & Ch'ongjin, Kyongsong & 羅南, 農戋洞 & 41.7 & $\mathrm{~N}$ & 129.7 & $\mathrm{E}$ \\
\hline Aug. 22, 1931 & Hamgyong-bukto & Kyongsong & 冠帽峰 & 41.5 & $\mathrm{~N}$ & 129.0 & $\mathrm{E}$ \\
\hline Sep. 11,1931 & Hamgyong-bukto & Ch'ongjin & 羅南 & 41.7 & $\mathrm{~N}$ & 129.7 & $\mathrm{E}$ \\
\hline May 3, 1932 & Hamgyong-bukto & Ch'ongjin & 羅南 西北側 & 41.7 & $\mathrm{~N}$ & 129.7 & $\mathrm{E}$ \\
\hline May 17,1932 & Hamgyong-bukto & Ch'ongjin & 羅南附近, 東南側 & 41.7 & $\mathrm{~N}$ & 129.7 & $\mathrm{E}$ \\
\hline May 29, 1932 & Hamgyong-bukto & Kyongsong & 北實峰 & 41.8 & $\mathrm{~N}$ & 129.5 & $\mathrm{E}$ \\
\hline June 4, 1932 & Hamgyong-bukto & Ch'ongjin & 羅南東南側 山地 & 41.7 & $\mathrm{~N}$ & 129.7 & $\mathrm{E}$ \\
\hline June $12-19,1932$ & Hamgyong-bukto & Ch'ongjin & 羅南 北面側 山地 & 41.7 & $\mathrm{~N}$ & 129.7 & $\mathrm{E}$ \\
\hline June 21-23, 1932 & Hamgyong-bukto & Ch'ongjin & 羅南, 羅南 西北側 & 41.7 & $\mathrm{~N}$ & 129.7 & $\mathrm{E}$ \\
\hline July, 1932 & Hamgyong-bukto & Ch'ongjin & 羅南 東南側 山地 & 41.7 & $\mathrm{~N}$ & 129.7 & $\mathrm{E}$ \\
\hline July $10-13,1932$ & Hamgyong-bukto & Ch'ongjin & 羅南 東側, 羅南 & 41.7 & $\mathrm{~N}$ & 129.7 & $\mathrm{E}$ \\
\hline July 18,1932 & Hamgyong-bukto & Kyongsong & 梧村面 九德洞 & 41.7 & $\mathrm{~N}$ & 129.7 & $\mathrm{E}$ \\
\hline July 28, 1932 & Hamgyong-bukto & Kyongsong & 鏡城郡 & 41.7 & $\mathrm{~N}$ & 129.5 & $\mathrm{E}$ \\
\hline July 30 - Aug. 2, 1932 & Hamgyong-bukto & Ch'ongjin & 渡正山 雷島, 見晴基 & 41.8 & $\mathrm{~N}$ & 129.3 & $\mathrm{E}$ \\
\hline Aug 2-7, 1932 & Hamgyong-bukto & Kyongsong & 冠帽峰, 冠帽峰 甫老川, 南河瑞 & 41.5 & $\mathrm{~N}$ & 129.0 & $\mathrm{E}$ \\
\hline Aug. 12, 1932 & Hamgyong-bukto & Ch'ongjin & 羅南 & 41.7 & $\mathrm{~N}$ & 129.7 & $\mathrm{E}$ \\
\hline Aug. 12, 1932 & Hamgyong-bukto & Ch'ongjin & 羅南 & 41.7 & $\mathrm{~N}$ & 129.7 & $\mathrm{E}$ \\
\hline Aug. $25-28,1932$ & Hamgyong-bukto & Onsong, Ch'ongjin & 慶興 西水羅, 羅南 東側 濕原 & 42.3 & $\mathrm{~N}$ & 130.6 & E \\
\hline Sep. 1, 1932 & Hamgyong-bukto & Myongch'on & 雪嶺 & 41.7 & $\mathrm{~N}$ & 129.2 & $\mathrm{E}$ \\
\hline
\end{tabular}


Appendix 5. Continued.

\begin{tabular}{|c|c|c|c|c|c|c|c|}
\hline Date & Province/City & County & gazetter & lat. & & long. & \\
\hline Sep. 12, 1932 & Hamgyong-bukto & Kyongsong & 南下石山 & 41.8 & $\mathrm{~N}$ & 129.4 & $\mathrm{E}$ \\
\hline Aug $17-19,1932$ & Hamgyong-bukto & Ch'ongjin & 羅南 北側 & 41.7 & $\mathrm{~N}$ & 129.7 & $\mathrm{E}$ \\
\hline Aug. $27-30,1932$ & Hamgyong-bukto & Ch'ongjin & 羅南 東側, 龍城面 & 41.7 & $\mathrm{~N}$ & 129.7 & $\mathrm{E}$ \\
\hline Oct. 3, 1932 & Hamgyong-bukto & Ch'ongjin & 羅南 南側, 西北側 & 41.7 & $\mathrm{~N}$ & 129.7 & $\mathrm{E}$ \\
\hline Feb. 18, 1933 & Hamgyong-bukto & Ch'ongjin & 羅南 & 41.7 & $\mathrm{~N}$ & 129.7 & $\mathrm{E}$ \\
\hline Mar. 19, 1933 & Hamgyong-bukto & Ch'ongjin & 羅南 & 41.7 & $\mathrm{~N}$ & 129.7 & $\mathrm{E}$ \\
\hline Apr. $21-22$ & Hamgyong-bukto & Ch'ongjin & 羅南 & 41.7 & $\mathrm{~N}$ & 129.7 & $\mathrm{E}$ \\
\hline Apr. 25-29, 1933 & Hamgyong-bukto & Ch'ongjin & 羅南, 羅南 支庫前 & 41.7 & $\mathrm{~N}$ & 129.7 & $\mathrm{E}$ \\
\hline May 2-9, 1933 & Hamgyong-bukto & Ch'ongjin & $\begin{array}{l}\text { 輸城, 羅南西北谷, 鐘城郡豊城面南南洞, } \\
\text { 支庫谷, 羅南東南側 }\end{array}$ & 41.8 & $\mathrm{~N}$ & 129.7 & $\mathrm{E}$ \\
\hline May 13-21, 1933 & Hamgyong-bukto & Ch'ongjin & $\begin{array}{l}\text { 羅南,羅南西北谷,羅南一里峯,渡正山, } \\
\text { 羅南西村農園,,羅南, 東南側 }\end{array}$ & 41.7 & $\mathrm{~N}$ & 129.7 & $\mathrm{E}$ \\
\hline May 22, 1933 & Hamgyong-bukto & Kyongsong & 梧村面 檜鄉洞 & 41.7 & $\mathrm{~N}$ & 129.6 & E \\
\hline May 23-26, 1933 & Hamgyong-bukto & Ch'ongjin & 羅南 東南, 羅南 & 41.7 & $\mathrm{~N}$ & 129.7 & $\mathrm{E}$ \\
\hline May 29-30, 1933 & Hamgyong-bukto & Kyongsong & 檜鄉洞 & 41.7 & $\mathrm{~N}$ & 129.6 & $\mathrm{E}$ \\
\hline June $1-2,1933$ & Hamgyong-bukto & Ch'ongjin & 羅南, 羅南 西北側 & 41.7 & $\mathrm{~N}$ & 129.7 & $\mathrm{E}$ \\
\hline June 3, 1933 & Hamgyong-bukto & Kyongsong & 梧村面 檜鄉洞, 九德洞 & 41.7 & $\mathrm{~N}$ & 129.6 & E \\
\hline June 4-6, 1933 & Hamgyong-bukto & Ch'ongjin & 羅南 & 41.7 & $\mathrm{~N}$ & 129.7 & $\mathrm{E}$ \\
\hline June $10-14,1933$ & Hamgyong-bukto & Ch'ongjin & 清津- 羅南 間, 羅南, 羅南 東南側 & 41.7 & $\mathrm{~N}$ & 129.7 & $\mathrm{E}$ \\
\hline June 30, 1933 & Hamgyong-bukto & Ch'ongjin & 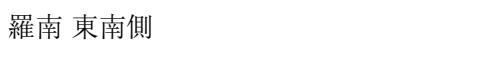 & 41.7 & $\mathrm{~N}$ & 129.7 & E \\
\hline July 5,1933 & Hamgyong-bukto & Kyongsong & 南下石山, 梧村堡, 鏡城 & 41.8 & $\mathrm{~N}$ & 129.4 & $\mathrm{E}$ \\
\hline July 21,1933 & Hamgyong-bukto & Kyongsong & 朱乙溫,冠帽峰, 將軍臺, & 41.6 & $\mathrm{~N}$ & 129.6 & E \\
\hline July 26,1933 & Hamgyong-bukto & Kyongsong & 冠帽峯 頂上 & 41.5 & $\mathrm{~N}$ & 129.0 & $\mathrm{E}$ \\
\hline July 26-Aug 1.1933 & Ryanggang & Samjiyon & $\begin{array}{l}\text { 白頭山,森林限界, } \\
\text { 白頭山(頂上 - 天池),松花江 }\end{array}$ & 42.0 & $\mathrm{~N}$ & 128.1 & $\mathrm{E}$ \\
\hline Aug. 4-7, 1933 & Hamgyong-bukto & Myongch'on & 朱南面 黃雪嶺, 雪嶺 & 41.5 & $\mathrm{~N}$ & 129.3 & $\mathrm{E}$ \\
\hline Aug. 21-23, 1933 & Hamgyong-bukto & Ch'ongjin & 羅南 陸軍, 羅南 & 41.7 & $\mathrm{~N}$ & 129.7 & E \\
\hline Sep. 9, 1933 & Hamgyong-bukto & Ch'ongjin & 羅南 西側 & 41.7 & $\mathrm{~N}$ & 129.6 & $\mathrm{E}$ \\
\hline Sep. $21-25,1933$ & Hamgyong-bukto & Kyongsong & 冠帽峰, 朱乙溫 & 41.5 & $\mathrm{~N}$ & 129.0 & $\mathrm{E}$ \\
\hline Oct. 16,1933 & Hamgyong-bukto & Ch'ongjin & 羅南 & 41.7 & $\mathrm{~N}$ & 129.7 & $\mathrm{E}$ \\
\hline Apr. 19, 1934 & Hamgyong-bukto & Ch'ongjin & 羅南 東側 & 41.7 & $\mathrm{~N}$ & 129.7 & $\mathrm{E}$ \\
\hline May 10, 1934 & Hamgyong-bukto & Ch'ongjin & 羅南, 羅南 西北側 & 41.7 & $\mathrm{~N}$ & 129.7 & $\mathrm{E}$ \\
\hline May 16, 1934 & Hamgyong-bukto & Ch'ongjin & 羅南 西側 ～～～～～～～ & 41.7 & $\mathrm{~N}$ & 129.6 & $\mathrm{E}$ \\
\hline May 29-June 5, 1934 & Hamgyong-bukto & Kyongsong & 朱乙溫(甫上-南河瑞), 冠帽峰 & 41.6 & $\mathrm{~N}$ & 129.6 & $\mathrm{E}$ \\
\hline July 5, 1934 & Hamgyong-bukto & Kyongsong & 農圃洞 & 41.8 & $\mathrm{~N}$ & 129.8 & $\mathrm{E}$ \\
\hline July 8,1934 & Hamgyong-bukto & Ch'ongjin & 羅南 & 41.7 & $\mathrm{~N}$ & 129.7 & $\mathrm{E}$ \\
\hline July 13, 1934 & Hamgyong-bukto & Kyongsong & 朱乙溫面, 羅南 & 41.6 & $\mathrm{~N}$ & 129.6 & $\mathrm{E}$ \\
\hline Aug, 1934 & Hamgyong-bukto & Kyongsong & 巨務德, 甫上洞 附近 & 41.6 & $\mathrm{~N}$ & 129.6 & $\mathrm{E}$ \\
\hline Aug. 4, 1934 & Hamgyong-bukto & Ch'ongjin & 羅南 & 41.7 & $\mathrm{~N}$ & 129.7 & $\mathrm{E}$ \\
\hline Aug. 18-19, 1934 & Hamgyong-bukto & Kyongsong & 東村 海岸 (鏡城 街道), 鏡城 街道, 鏡城 & 41.9 & $\mathrm{~N}$ & 129.9 & E \\
\hline
\end{tabular}


Appendix 5. Continued.

\begin{tabular}{|c|c|c|c|c|c|c|c|}
\hline Date & Province/City & County & gazetter & lat. & & long. & \\
\hline Oct. 17,1934 & Hamgyong-bukto & Ch'ongjin & 羅南 & 41.7 & $\mathrm{~N}$ & 129.7 & $\mathrm{E}$ \\
\hline Mar. 25, 1935 & Hamgyong-bukto & Ch'ongjin & 羅南 & 41.7 & $\mathrm{~N}$ & 129.7 & $\mathrm{E}$ \\
\hline Apr. $10-15,1935$ & Hamgyong-bukto & Ch'ongjin & 羅南,羅南西北測, 新社 & 41.7 & $\mathrm{~N}$ & 129.7 & $\mathrm{E}$ \\
\hline Apr. 19-22, 1935 & Hamgyong-bukto & Ch'ongjin & 羅南支庫前 & 41.7 & $\mathrm{~N}$ & 129.7 & $\mathrm{E}$ \\
\hline Apr. 28,1935 & Hamgyong-bukto & Ch'ongjin & 羅南 東南側 & 41.7 & $\mathrm{~N}$ & 129.7 & $\mathrm{E}$ \\
\hline Apr. 29, 1935 & Hamgyong-bukto & Kyongsong & 鏡城 城見橋 & 42.8 & $\mathrm{~N}$ & 129.8 & $\mathrm{E}$ \\
\hline May 6-9, 1935 & Hamgyong-bukto & Kyongsong & 羅南 梧上洞 & 41.7 & $\mathrm{~N}$ & 129.6 & $\mathrm{E}$ \\
\hline May 13,1935 & Hamgyong-bukto & Kyongsong & 鏡城 & 42.8 & $\mathrm{~N}$ & 129.8 & E \\
\hline May 14,1935 & Hamgyong-bukto & Ch'ongjin & 羅南 西側, 羅南 花白邑 & 41.7 & $\mathrm{~N}$ & 129.6 & E \\
\hline May 23-27, 1935 & Hamgyong-bukto & Kyongsong & 梧上洞, 朱乙 & 41.7 & $\mathrm{~N}$ & 129.6 & $\mathrm{E}$ \\
\hline June 12, 1935 & Hamgyong-bukto & Ch'ongjin & 羅南 & 41.7 & $\mathrm{~N}$ & 129.7 & $\mathrm{E}$ \\
\hline June 13, 1935 & Hamgyong-bukto & Kyongsong & 鏡城 & 42.8 & $\mathrm{~N}$ & 129.8 & $\mathrm{E}$ \\
\hline June 18,1935 & Hamgyong-bukto & Kyongsong & 羅南教外九德洞 & 41.7 & $\mathrm{~N}$ & 129.7 & $\mathrm{E}$ \\
\hline June $21-23,1935$ & Hamgyong-bukto & Onsong, Kyongsong & 穩城郡 㽪山, 元師台, 梧上洞 & 42.8 & $\mathrm{~N}$ & 130.0 & $\mathrm{E}$ \\
\hline June 25, 1935 & Rason & Rajin & 獨津 海岸 & 41.7 & $\mathrm{~N}$ & 129.7 & $\mathrm{E}$ \\
\hline June 28, 1935 & Hamgyong-bukto & Kyongsong & 鏡城 丁氏邱 & 41.6 & $\mathrm{~N}$ & 129.6 & E \\
\hline June $29-30,1935$ & Hamgyong-bukto & Ch'ongjin, Kyongsong & 鏡城 - 羅南, 鏡城 - 羅南, 鏡城 & 41.7 & $\mathrm{~N}$ & 129.7 & $\mathrm{E}$ \\
\hline July 1,1935 & Hamgyong-bukto & Kyongsong & 鏡城, 九德洞 & 42.8 & $\mathrm{~N}$ & 129.8 & $\mathrm{E}$ \\
\hline July 4, 1935 & Hamgyong-bukto & Ch'ongjin & 羅南川 & 41.7 & $\mathrm{~N}$ & 129.7 & $\mathrm{E}$ \\
\hline July 6,1935 & Rason & Rajin & 獨津 & 41.7 & $\mathrm{~N}$ & 129.7 & $\mathrm{E}$ \\
\hline July 7-11, 1935 & Hamgyong-bukto & Ch'ongjin & 羅南, 羅南 生馬町 & 41.7 & $\mathrm{~N}$ & 129.7 & $\mathrm{E}$ \\
\hline July 21, 1935 & Hamgyong-bukto & Ch'ongjin & 羅南 & 41.7 & $\mathrm{~N}$ & 129.7 & $\mathrm{E}$ \\
\hline July $23-29,1935$ & Hamgyong-bukto & Kyongsong & $\begin{array}{l}\text { 九德洞-黃雪嶺,甫上洞, 儉舞德-南河洞梅 } \\
\text { 岡山-金谷洞車砲谷, 南河洞梅岡山, } \\
\text { 朱北,甫上溫泉場 }\end{array}$ & 41.7 & $\mathrm{~N}$ & 129.7 & E \\
\hline Aug. 3-7, 1935 & Hamgyong-bukto & Ch'ongjin & 羅南支庫 & 41.7 & $\mathrm{~N}$ & 129.7 & $\mathrm{E}$ \\
\hline Aug. 9-21, 1935 & Hamgyong-bukto & Ch'ongjin & 羅南, 九德洞, 農固洞, 阿陽洞 & 41.7 & $\mathrm{~N}$ & 129.7 & $\mathrm{E}$ \\
\hline Aug. 23-30, 1935 & Hamgyong-bukto & Kyongsong & 鏡城 & 42.8 & $\mathrm{~N}$ & 129.8 & $\mathrm{E}$ \\
\hline Aug. 30-Sep. 1, 1935 & Hamgyong-bukto & Ch'ongjin & 羅南, 漁遊洞 & 41.7 & $\mathrm{~N}$ & 129.7 & $\mathrm{E}$ \\
\hline Sep. 11, 1935 & Hamgyong-bukto & Ch'ongjin & 羅南 & 41.7 & $\mathrm{~N}$ & 129.7 & $\mathrm{E}$ \\
\hline Sep. 13, 1935 & Hamgyong-bukto & Kyongsong & 鏡城,羅南 & 42.8 & $\mathrm{~N}$ & 129.8 & $\mathrm{E}$ \\
\hline Sep. $17-21,1935$ & Hamgyong-bukto & Kyongsong & 梧上洞-坂幕-南下石山 & 41.7 & $\mathrm{~N}$ & 129.6 & $\mathrm{E}$ \\
\hline Sep. 25-Oct. 10, 1935 & Hamgyong-bukto & Ch'ongjin & 羅南 & 41.7 & $\mathrm{~N}$ & 129.7 & $\mathrm{E}$ \\
\hline Mar. 22, 1936 & Hamgyong-bukto & Kyongsong & 朱乙 & 41.6 & $\mathrm{~N}$ & 129.6 & $\mathrm{E}$ \\
\hline Apr. 25, 1936 & Hamgyong-bukto & Onsong & 鏡城 觀海寺 & 42.1 & $\mathrm{~N}$ & 130.1 & $\mathrm{E}$ \\
\hline May 4, 1936 & Ryanggang & Paegam & 咸北道廳 & 41.3 & $\mathrm{~N}$ & 128.9 & $\mathrm{E}$ \\
\hline May 13, 1936 & Hamgyong-bukto & Onsong & 鏡城 觀海寺 & 42.1 & $\mathrm{~N}$ & 130.1 & $\mathrm{E}$ \\
\hline May 18, 1936 & Hamgyong-bukto & Kyongsong & 北實峰 & 41.8 & $\mathrm{~N}$ & 129.5 & E \\
\hline May 27, 1936 & Ryanggang & Paegam & 咸北道廳 & 41.3 & $\mathrm{~N}$ & 128.9 & $\mathrm{E}$ \\
\hline June 5-16, 1936 & Hamgyong-bukto & Kyongsong & 朱乙溫 梅香洞, 朱乙 - 甫上, 冠帽峰 & 41.5 & $\mathrm{~N}$ & 129.4 & $\mathrm{E}$ \\
\hline June 22-28, 1936 & Hamgyong-bukto & Kyongsong, Ch'ongjin & 鏡城, 羅南, 朱乙 & 42.8 & $\mathrm{~N}$ & 129.8 & $\mathrm{E}$ \\
\hline
\end{tabular}


Appendix 5. Continued.

\begin{tabular}{|c|c|c|c|c|c|c|c|}
\hline Date & Province/City & County & gazetter & lat. & & long. & \\
\hline July 2-8, 1936 & Hamgyong-bukto & Onsong & $\begin{array}{l}\text { 慶興 鏡城 豊谷 鎭城郡 南山面 新興 } \\
\text { 鐘城郡 鶴浦-行營 }\end{array}$ & 42.5 & $\mathrm{~N}$ & 130.3 & E \\
\hline July $10-12,1936$ & Hamgyong-bukto & Hoeryong, Saebyol & 鏡城 行營 - 龍山洞, 龍溪 & 42.6 & $\mathrm{~N}$ & 130.0 & E \\
\hline July 15, 1936 & Hamgyong-bukto & Hoeryong & 會寧 鳳儀大澤洞 & 42.4 & $\mathrm{~N}$ & 129.8 & E \\
\hline July $22-25,1936$ & Hamgyong-bukto & Kyongsong & 朱乙 & 41.6 & $\mathrm{~N}$ & 129.6 & $\mathrm{E}$ \\
\hline July 28-30, 1936 & Hamgyong-bukto & Musan & $\begin{array}{l}\text { 茂山, 茂山 新站, } \\
\text { 延上面 九州帝大北鮮演習林 }\end{array}$ & 42.2 & $\mathrm{~N}$ & 129.2 & $\mathrm{E}$ \\
\hline Aug. 2, 1936 & Hamgyong-bukto & Kyongsong & 鏡城 & 42.8 & $\mathrm{~N}$ & 129.8 & E \\
\hline Aug. 3, 1936 & Hamgyong-bukto & Musan & 漁下面, 茂山,延上面 & 42.1 & $\mathrm{~N}$ & 129.3 & $\mathrm{E}$ \\
\hline Aug. 10-12, 1936 & Hamgyong-bukto & Ch'ongjin, Kyongsong & 羅南, 鏡城, 鏡城郡 & 41.7 & $\mathrm{~N}$ & 129.7 & E \\
\hline Aug. 13-14, 1936 & Hamgyong-bukto & Puryong & 富寧 上峴 - 石幕 - 席帽, 富寧石幕 - 靑岩 & 42.0 & $\mathrm{~N}$ & 129.7 & $\mathrm{E}$ \\
\hline Aug. 15-16, 1936 & Hamgyong-bukto & Ch'ongjin, Kyongsong & 富寧青岩-連川,富寧連川 - 水坪, 朱乙 & 41.8 & $\mathrm{~N}$ & 129.8 & $\mathrm{E}$ \\
\hline Aug. 18, 1936 & Hamgyong-bukto & Puryong & 富寧 水呠 - 西里洞 (淸津) & 41.8 & $\mathrm{~N}$ & 129.8 & E \\
\hline Au.g 20-25, 1936 & Hamgyong-bukto & $\begin{array}{l}\text { Ch'ongjin, Onsong, } \\
\text { Kyongsong }\end{array}$ & $\begin{array}{l}\text { 富寧 素清, 觀海寺, 朱乙, } \\
\text { 鏡城 觀海寺, 鏡城 } \\
\text { 駱駝峰, 梧上洞 }\end{array}$ & 41.8 & $\mathrm{~N}$ & 129.8 & E \\
\hline Aug. 29-31, 1936 & Hamgyong-bukto & Kyongsong & 朱乙, 城町 & 41.6 & $\mathrm{~N}$ & 129.6 & $\mathrm{E}$ \\
\hline Sep. 2-6,1936 & Hamgyong-bukto & Kyongsong & 朱南面 朱乙 & 41.6 & $\mathrm{~N}$ & 129.5 & $\mathrm{E}$ \\
\hline Sep. $13-18,1936$ & Hamgyong-bukto & Kyongsong & 朱乙, 鏡城 & 41.6 & $\mathrm{~N}$ & 129.6 & $\mathrm{E}$ \\
\hline Oct. 2, 1936 & Hamgyong-bukto & Kyongsong & 甫上- 城町 & 41.8 & $\mathrm{~N}$ & 129.4 & $\mathrm{E}$ \\
\hline Oct. 13,1936 & Hamgyong-bukto & Kyongsong & 鏡城 & 42.8 & $\mathrm{~N}$ & 129.8 & $\mathrm{E}$ \\
\hline Oct. 17,1936 & Rason & Rajin & 獨津, 獨津 海岸 & 41.7 & $\mathrm{~N}$ & 129.7 & $\mathrm{E}$ \\
\hline May 17, 1937 & Ryanggang & Paegam & 咸北道廳 & 41.6 & $\mathrm{~N}$ & 129.6 & $\mathrm{E}$ \\
\hline May 28, 1937 & Hamgyong-bukto & Ch'ongjin & 輸城 & 41.8 & $\mathrm{~N}$ & 129.7 & $\mathrm{E}$ \\
\hline June 3-4, 1937 & Hamgyong-bukto & Ch'ongjin & 輸城 & 41.8 & $\mathrm{~N}$ & 129.7 & E \\
\hline June 10, 1937 & Hamgyong-bukto & Onsong & 穩城 上和洞 & 42.9 & $\mathrm{~N}$ & 130.0 & $\mathrm{E}$ \\
\hline June $19-28,1937$ & Hamgyong-bukto & Kimch'aek & 城津, 龍台, 晚春, 松興, 防洞, 漁遊洞 & 40.7 & $\mathrm{~N}$ & 129.2 & E \\
\hline July 4, 1937 & Ryanggang & Paegam & 咸北道廳 & 41.3 & $\mathrm{~N}$ & 128.9 & E \\
\hline July 6-7, 1937 & Rason & Rajin & 淃風里, 西水羅 & 42.3 & $\mathrm{~N}$ & 130.3 & E \\
\hline July 9, 1937 & Rason & Rajin & 赤島 & 42.3 & $\mathrm{~N}$ & 130.5 & E \\
\hline July 9, 1937 & Hamgyong-bukto & Ch'ongjin & 漁遊洞 & 41.8 & $\mathrm{~N}$ & 129.6 & $\mathrm{E}$ \\
\hline July 12, 1937 & Rason & Rajin & 赤島 & 42.3 & $\mathrm{~N}$ & 130.5 & E \\
\hline Aug. 5, 1937 & Hamgyong-bukto & & 南大溪 & 41.1 & $\mathrm{~N}$ & 129.2 & E \\
\hline Aug. 7-12, 1937 & Ryanggang & Paegam & 大澤-合水 & 41.2 & $\mathrm{~N}$ & 128.8 & E \\
\hline Aug. 15, 1937 & Rason & Rajin & 寬谷 & 42.3 & $\mathrm{~N}$ & 130.4 & $\mathrm{E}$ \\
\hline Aug. 30, 1937 & Hamgyong-bukto & Kilchu & 頭流山 & 41.2 & $\mathrm{~N}$ & 128.8 & $\mathrm{E}$ \\
\hline Sep. 11-12, 1937 & Ryanggang & Paegam & 白岩 & 41.2 & $\mathrm{~N}$ & 128.8 & $\mathrm{E}$ \\
\hline Sep. 15-16, 1937 & Hamgyong-bukto & Kyongsong & 豊城面 南夕洞, 修鍊所 & 41.6 & $\mathrm{~N}$ & 129.7 & $\mathrm{E}$ \\
\hline Sep. 22-25, 1937 & Hamgyong-bukto & Ch'ongjin & 漁遊洞, 鏡城 & 41.8 & $\mathrm{~N}$ & 129.6 & E \\
\hline Sep. 28-29, 1937 & Hamgyong-bukto & Ch'ongjin & 淸津 & 41.8 & $\mathrm{~N}$ & 129.8 & E \\
\hline
\end{tabular}


Appendix 5. Saito, T.'s itinerary from 1929 to 1942 in Hamgyong-bukto and Ryanggang of North Korea(DPRK).

\begin{tabular}{|c|c|c|c|c|c|c|c|}
\hline Date & Province/City & County & gazetter & lat. & & long. & \\
\hline Oct. $6-9,1937$ & Hamgyong-bukto & Onsong & 稳城 上和洞, 穩城郡 瞄山 & 42.9 & $\mathrm{~N}$ & 130.0 & $\mathrm{E}$ \\
\hline Oct. 17,1937 & Ryanggang & Paegam & 北倉坪 & 41.7 & $\mathrm{~N}$ & 128.8 & $\mathrm{E}$ \\
\hline May 9-12, 1938 & Hamgyong-bukto & Kimch'aek & 鶴西面 德仁 & 40.9 & $\mathrm{~N}$ & 129.2 & $\mathrm{E}$ \\
\hline May 24-28, 1938 & Hamgyong-bukto & Musan & 茂山, 農事洞, 三長 附近, 茂山嶺 & 42.2 & $\mathrm{~N}$ & 129.2 & $\mathrm{E}$ \\
\hline June $16-19,1938$ & Hamgyong-bukto & Hoeryong & 行營, 慶源郡 龍德面, 䇺城郡 鼠山 & 42.5 & $\mathrm{~N}$ & 129.9 & $\mathrm{E}$ \\
\hline June $26-30,1938$ & Hamgyong-bukto & Undok & 灰岩, 松眞山 & 42.5 & $\mathrm{~N}$ & 130.4 & $\mathrm{E}$ \\
\hline July $15-19,1938$ & Ryanggang & Taehongdan & 新德 - 榆坪洞, 延岩 & 41.9 & $\mathrm{~N}$ & 128.9 & $\mathrm{E}$ \\
\hline Aug. 25, 1938 & Hamgyong-bukto & Musan & 茂山 & 42.2 & $\mathrm{~N}$ & 129.2 & $\mathrm{E}$ \\
\hline Oct. $15-18,1938$ & Hamgyong-bukto & Myongch'on & 明川, 梨坪, 熊店, 甘吐峯 & 41.1 & $\mathrm{~N}$ & 129.4 & $\mathrm{E}$ \\
\hline Apr. 23, 1939 & Hamgyong-bukto & Kyongsong & 鏡城 & 42.8 & $\mathrm{~N}$ & 129.8 & $\mathrm{E}$ \\
\hline July 20-Aug. 2, 1942 & Ryanggang & Samjiyon & $\begin{array}{l}\text { 白頭山 森林限界-白頭山 大將峰-天池, } \\
\text { 白頭山 無頭峰-大將峰-天地 }\end{array}$ & 42.0 & $\mathrm{~N}$ & 128.1 & E \\
\hline Oct. 5-6, 1942 & Hamgyong-bukto & Ch'ongjin & 淸津 高抹山 西側, 東側 & 41.8 & $\mathrm{~N}$ & 129.8 & $\mathrm{E}$ \\
\hline
\end{tabular}

Appendix 6. Okuyama, S.'s itinerary for the 1940 in Hamgyong-namdo of North Korea(DPRK).

\begin{tabular}{|c|c|c|c|c|c|c|c|}
\hline Date & Province/City & County & gazetteer & lat & & long & \\
\hline Aug. 7-9, 1940 & Kangwon-do & Kumgang & 金剛山 內金剛 毘盧峯 & 38.6 & $\mathrm{~N}$ & 128.1 & $\mathrm{E}$ \\
\hline Aug. 11, 1940 & Hamgyong-namdo & Hamhung & 咸興 歸州寺 & 39.9 & $\mathrm{~N}$ & 127.6 & $\mathrm{E}$ \\
\hline Aug. 14-16, 1940 & Hamgyong-namdo & Pujon & 赴戰高原, 雲水嶺, 漢岱里, 遮日峯, 蓋馬高原 & 40.5 & $\mathrm{~N}$ & 127.5 & $\mathrm{E}$ \\
\hline Aug. 17, 1940 & Hamgyong-namdo & Chongp'yong & 西湖津 海岸 & 39.8 & $\mathrm{~N}$ & 127.65 & $\mathrm{E}$ \\
\hline Aug. 17, 1940 & Hamgyong-namdo & Hamhung & 威興 & 39.9 & $\mathrm{~N}$ & 127.5 & $\mathrm{E}$ \\
\hline
\end{tabular}

